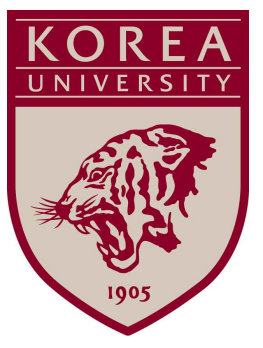

Discussion Paper Series

No. 0906

March 2009

\title{
Dynamic Treatment Effect Analysis of TV Effects on Child Cognitive Development
}

\author{
Fali Huang and Myoung-jae Lee
}

The Institute of Economic Research - Korea University

Anam-dong, Sungbuk-ku, Seoul, 136-701, South Korea, Tel: (82-2) 3290-1632, Fax: (82-2) 928-4948

Copyright (C) 2009 IER. 


\section{Dynamic Treatment Effect Analysis of TV Effects on Child Cognitive Development}

(December 5, 2008)

\author{
Fali Huang \\ School of Economics \\ Singapore Management University \\ 90 Stamford Road, Singapore 178903 \\ flhuang@smu.edu.sg; \\ fax: 65-6828-0833
}

\author{
Myoung-jae Lee* \\ Department of Economics \\ Korea University \\ Anam-dong, Sungbuk-ku \\ Seoul 136-701, South Korea \\ myoungjae@korea.ac.kr \\ phone: 82-2-3290-2229
}

We investigate whether TV watching at ages 6-7 and 8-9 affects cognitive development measured by math and reading scores at ages 8-9, using a rich childhood longitudinal sample from NLSY79. Dynamic panel data models are estimated to handle the unobserved child-specific factor, endogeneity of TV watching, and dynamic nature of the causal relation. A special emphasis is put on the last aspect where TV watching affects cognitive development which in turn affects the future TV watching. When this feedback occurs, it is not straightforward to identify and estimate the TV effect. We develop a two-stage estimation method which can deal with the feedback feature; we also apply the "standard" econometric panel data approaches. Overall, for math score at ages 8-9, we find that watching TV during ages 6-7 and 8-9 has a negative total effect mostly due to a large negative effect of TV watching at the younger ages 6-7. For reading score, there are evidences that watching no more than two hours TV per day has a positive effect whereas the effect is negative outside this range. In both cases, however, the effect magnitudes are economically small.

Key Words: TV watching, treatment effect, panel data, dynamic model with feedback.

JEL Classification Numbers: C33, I20, J13, E60.

* Corresponding Author.

** The authors are grateful to the anonymous referees and the Coeditor Manuel Arellano for their detailed comments. 


\section{Introduction}

The U.S. children spend the second largest chunk of their waking time on watching TV (Juster and Stafford, 1991). That is, the most time-consuming activity after attending school is TV watching. For example, an average eight-year old in NLSY79 (National Longitudinal Survey of Youth 1979) child sample spends about 25 hours per week in front of the television. Despite the widespread use of computers and the internet, television (TV) remains the dominant form of media in children's lives. A recent nationally representative survey found that 8-18 year-olds watch an average of 3 hours of television a day compared with 1 hour a day spent on recreational computer use (Rideout et al. 2005; see also Chernin and Linebarger 2005 and Pecora et al. 2006). Not surprisingly, the public and parents are concerned about potentially bad effects of child TV watching. The goal of this paper is to find the effects of TV watching on child cognitive development measured by standardized mathematics and reading scores.

The cognitive development in early childhood may be crucial to human capital formation in later years, since "success or failure at this stage feeds into success or failure in school which in turn leads to success or failure in post-school learning" (Heckman 1999). This relation is just one of many such relations where something happened far back has long-term lingering effects. For instance, the skill heterogeneity at age 16 is shown to account for as much as $90 \%$ of the total variation of one's lifetime earnings by Keane and Wolpin (1997).

There are, however, a number of difficulties in establishing the causal link between TV watching and cognitive development. First, inappropriate home and school inputs (for instance, economically and intellectually deficient environments) may induce both more TV watching and lower test scores. This is an omitted variable (or 'unobserved confounder') problem, which can be resolved by detailed data with sufficient "environmental" control variables. Second, children and the parents may share predispositions for certain habits and behaviors that cannot be measured. This is an 'individual-specific effect' problem, which may be overcome with panel data. Third, TV watching can affect cognitive development, which can in turn affect the future TV watching. This is an issue of dynamic treatment effects with feedback, calling for a proper dynamic model and estimation method. With a rich childhood longitudinal sample from NLSY79 child data that have not only child characteristics and family background variables but also detailed home and school inputs in the current and 
earlier periods, we will estimate dynamic models to overcome these problems.

Possibly due to the above difficulties, there has been hardly any research in the economics literature for the effects of TV watching on cognitive development. An exception is Zavodny (2006) who studies the effects of TV watching for high school students and reviews related studies in other social sciences. Her main finding is that, although there exist significantly negative effects in cross-sectional results, TV watching has no effect on test scores once individual-specific effects are taken into account. Differently from Zavodny (2006) who deals with individual-specific effects with panel data and family-specific effects with twins and siblings data, we tackle the dynamic nature of the causal relation; also we focus on young children, not on high school students. Another exception is Gentzkow and Shapiro (2008) who use the well known 'Coleman study' data and difference-in-differences methods, taking advantage of different TV-introduction timings across regions. Their preferred estimate shows a small (about $2 \%$ of one standard deviation) but positive effect of TV watching on test scores at ages 11-17. As in Zavodny (2006), this study does not address the dynamic nature of the causal relation.

The impact of TV viewing on child development has been studied also in the literature of communication, child development, and other psychological domains. These non-economic literature tends to focus more on content-specific studies through experiments and detailed routes for how TV viewing may affect child development. As far as the effects of TV viewing hours are concerned, the statistical analysis is mostly on the correlation rather than the causal relationship, and most studies found modest and negative associations of TV viewing with cognitive development of young children (Van Evra 2004, Zimmerman and Christakis 2005, and Anderson 2005).

Putting our main findings in advance, TV effects are statistically significant, but economically small in terms of their magnitude. The directions of the effects vary across ages, and differ for math and reading scores - two different measures of cognitive development used in this paper. Our preferred estimates indicate that the total effect of TV watching during ages 6-7 and 8-9 is negative for math score at ages 8-9, where the 'indirect effect' of TV viewing at the younger ages 6-7 transmitted through the score at ages 6-7 is much larger than the direct effects of TV viewing at ages 6-7 and 8-9. For the reading score at ages 8-9, however, watching not more than two hours TV per day brings a small but positive effect than too much TV viewing. For example, watching two hours TV per day during ages 6-7 
and 8-9 reduces one's math score at ages 8-9 by $4 \%$ of one standard deviation, but increases one's reading score at ages $8-9$ by $3 \%$ of one standard deviation, compared with not watching TV at all.

This paper differs from the TV effect literature in economics on several grounds. First, we develop a two-stage procedure to deal with the dynamic feedback feature of TV watching on test scores. Second, we focus on the effects of TV watching for children at ages 8-9, who are younger than in the two studies mentioned above. Third, with many control variables including detailed home and school inputs, we still find significant concave/convex effects of TV watching on both scores based on conventional methods of least squares estimator (LSE) and fixed-effect models, which differs from Zavodny (2006). Additionally, when the dynamic feedback feature of earlier TV watching is taken into account, the estimated overall effects of TV watching at ages 6-7 and 8-9 are significantly negative for math score, mostly due to a large harmful effect of TV viewing at the early ages 6-7. This contrasts with the positive effects found by Gentzkow and Shapiro (2008). On the other hand, our results are consistent with these former studies on the small magnitudes of TV effects, and on the possible positive effects of TV viewing for reading score.

The rest of this paper is organized as follows. Section 2 reviews 'G-algorithm' used in biostatistics that can identify the desired full TV effects taking the dynamic causal feature into account, which then motivates our two-stage procedure using linear models. Section 3 presents typical econometric dynamic panel data approaches. Section 4 describes our data. Section 5 presents the empirical findings. Finally, Section 6 concludes.

\section{G-Algorithm and Linear-Model Two-Stage Procedure}

\subsection{G-Algorithm Basics}

Suppose

$$
\left(x_{i 0}^{\prime}, y_{i 0}, x_{i 1}^{\prime}, d_{i 1}, y_{i 1}, x_{i 2}^{\prime}, d_{i 2}, y_{i 2}\right), i=1, \ldots, N \text {, are observed and iid across } i=1, \ldots, N \text {. }
$$

We will often omit the subscript $i$ in the rest of this paper in view of the iid assumption. In each period, $x_{i t}$ is the "period- $t$ baseline" covariate which can affect the treatment $d_{i t}$ and response $y_{i t}$, and $d_{i t}$ then may affect $y_{i t}$. The dynamic framework is, omitting $x_{i t}$ 's, 
Figure 1

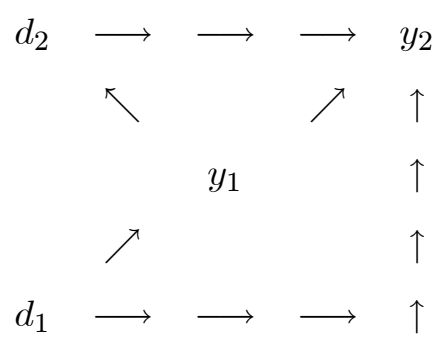

The feedback feature is $y_{1} \longrightarrow d_{2}: d_{2}$ gets adjusted after the interim response $y_{1}$ has been observed. This sounds natural: parents adjust their children's TV watching hours having seen their test scores, but the feedback feature $y_{1} \longrightarrow d_{2}$ makes $d_{2}$ non-randomized even if $d_{1}$ were so.

Define the 'potential responses' for the observed responses $y_{1}$ and $y_{2}$ :

$$
\begin{aligned}
y_{1}^{j} & : \text { when treatment } j \text { is given exogenously at time } 1, \\
y_{2}^{j k} & : \text { when treatments } j, k \text { are given exogenously at time } 1,2, \quad j, k \in[0, \infty) .
\end{aligned}
$$

With $d_{1}$ and $d_{2}$ observed, we have $y_{1}=y_{1}^{d_{1}}$ and $y_{2}=y_{2}^{d_{1} d_{2}}$; i.e., only the potential responses corresponding to the realized treatment levels are observed, and all the other potential responses - 'counter-factuals' - are not. Also define the 'potential treatment' for $d_{2}$ :

$$
d_{2}^{j} \text { : when treatment } j \text { is given exogenously at time } 1 \text { (thus } y_{1}^{j} \text { realized); }
$$

with $d_{1}$ observed, we have $d_{2}=d_{2}^{d_{1}}$.

Our goal is to find the mean effect $E\left(y_{2}^{j_{o} k_{o}}-y_{2}^{00}\right)$ for the intervened treatment 'profile' $\left(j_{o}, k_{o}\right)$ versus no treatment at all. Although the mean effect on some treated group may be also of interest, there are problems in identifying the effect on the treated unless essentially the treated is only for the first period; this is discussed in detail by Lechner and Miquel (2001). In this paper, we take the position that TV effect is of interest to the entire population, not just to some subpopulation. Nevertheless, if desired, our models allow interaction terms between the treatments and some elements of the covariates/lagged-responses, which can account for the effect on the subpopulation characterized by those elements.

Let

$$
X_{2} \equiv\left(x_{0}^{\prime}, y_{0}, x_{1}^{\prime}, x_{2}^{\prime}\right)^{\prime}
$$


and denote the conditional independence of $a$ and $b$ given $c$ as ' $a \amalg b \mid c$ '. Assume ' no unobserved confounder' (NUC):

$$
\begin{aligned}
& \text { NUC1 }: y_{2}^{j k} \amalg d_{1} \mid X_{2}, \quad \text { for } j=j_{o}, 0 \text { and } k=k_{o}, 0 \\
& \mathrm{NUC2}: \quad y_{2}^{j k} \amalg d_{2}^{j} \mid\left(d_{1}=j, y_{1}^{j}, X_{2}\right), \quad \text { for } j=j_{o}, 0 \text { and } k=k_{o}, 0 .
\end{aligned}
$$

If the interest is also in the effect of $d_{1}$ on $y_{1}$, following the usual static counter-factual causal framework, assume additionally

$$
\mathrm{NUC0}: y_{1}^{j} \amalg d_{1} \mid\left(x_{0}, y_{0}, x_{1}\right) .
$$

NUC1 holds if $d_{1}$ is determined by $X_{2}$ and some error term independent of $y_{2}^{j k}$ given $X_{2}$. Saying " $d_{1}$ determined by $X_{2}$ " may sound preposterous because parts of $X_{2}$ are realized after $d_{1}$, but the dependence between $d_{1}$ and those components of $X_{2}$ in NUC1 should be construed as $d_{1}$ being allowed to affect $y_{2}^{j k}$ through those components in $X_{2}$. If one finds NUC2 somewhat confusing, it may help to rephrase it with densities: with $f\left(y_{2 o}^{j k} \mid d_{2 o}^{j}, d_{1 o}, y_{1 o}^{j}, X_{2 o}\right)$ denoting the conditional density/probability of $y_{2}^{j k} \mid\left(d_{2}^{j}, d_{1}, y_{1}^{j}, X_{2}\right)$ evaluated at $\left(y_{2 o}^{j k}, d_{2 o}^{j}, d_{1 o}, y_{1 o}^{j}, X_{2 o}\right)$, NUC2 states

$$
f\left(y_{2 o}^{j k} \mid d_{2 o}^{j}, j, y_{1 o}^{j}, X_{2 o}\right) \text { does not change as } d_{2 o}^{j} \text { changes. }
$$

Both NUC1 and NUC2 are 'selection-on-observables', because NUC1 states that the $d_{1^{-}}$ selection is independent of $y_{2}^{j k}$ given the observable $X_{2}$, and NUC2 states that the $d_{2}^{j}$ selection is independent of $y_{2}^{j k}$ given the observable $\left(d_{1}=j, y_{1}^{j}, X_{2}\right)$.

G-algorithm (or G-estimation) under NUC is (see Robins, 1986 (with errata and appendum 1987), 1998, 1999 and the references therein)

$$
E\left(y_{2}^{j k} \mid X_{2}\right)=\int E\left(y_{2} \mid d_{1}=j, d_{2}=k, y_{1}, X_{2}\right) f\left(y_{1} \mid d_{1}=j, X_{2}\right) \partial y_{1}
$$

where $f\left(y_{1} \mid d_{1}=j, X_{2}\right)$ denotes the conditional density of $y_{1} \mid\left(d_{1}=j, X_{2}\right)$, ' $\partial$ ' is used for integration/differentiation to avoid the confusion with treatment $d$, and $y_{1}$ in (2.1) is an integration dummy, not a random variable.

The important point is that the right-hand side of (2.1) is identified and operational as it depends on observed variables, which means that $E\left(y_{2}^{j k} \mid X_{2}\right)$ is identified and can be 
estimated with the right-hand side. G-algorithm holds because the right-hand side of (2.1) is

$$
\begin{aligned}
& \int E\left(y_{2}^{j k} \mid d_{1}=j, d_{2}^{j}=k, y_{1}^{j}, X_{2}\right) f\left(y_{1}^{j} \mid d_{1}=j, X_{2}\right) \partial y_{1}^{j} \\
& =\int E\left(y_{2}^{j k} \mid d_{1}=j, y_{1}^{j}, X_{2}\right) f\left(y_{1}^{j} \mid d_{1}=j, X_{2}\right) \partial y_{1}^{j} \quad \text { (due to NUC2) } \\
& =E\left(y_{2}^{j k} \mid d_{1}=j, X_{2}\right) \quad\left(\text { for } y_{1}^{j}\right. \text { is integrated out) } \\
& =E\left(y_{2}^{j k} \mid X_{2}\right) \quad \text { (due to NUC1). }
\end{aligned}
$$

As NUC1 is invoked only at the last equality, if NUC1 does not hold, one may go for $E\left(y_{2}^{j k} \mid d_{1}=j, X_{2}\right)-E\left(y_{2}^{j 0} \mid d_{1}=j, X_{2}\right)$, which is the mean treatment effect on the "treated $\left(d_{1}=j\right)$ " — a kind of treatment effects in Lechner and Miquel (2001) as mentioned already.

In essence, G-algorithm starts with the mean of $y_{2}^{j k}$ for the subpopulation $\left(d_{1}=j, d_{2}=\right.$ $\left.k, y_{1}\right)$. The condition $d_{1}=j, d_{2}=k$ is needed because $y_{2}^{j k}$ is observed only for those with $d_{1}=j, d_{2}=k$, and $y_{1}$ is needed to account for the dynamic feedback. Then the subpopulation is generalized to the whole population (i.e., the selection problem ruled out) as $d_{1}=j$ and $d_{2}=k$ are removed by $\mathrm{NUC1}$ and $\mathrm{NUC} 2$, respectively, and $y_{1}$ is removed by integration.

Getting $E\left(y_{2}^{j_{o} k_{o}} \mid X_{2}\right)$ and $E\left(y_{2}^{00} \mid X_{2}\right)$ and then integrating out $X_{2}$, we obtain the desired

$$
E\left(y_{2}^{j_{o} k_{o}}-y_{2}^{00}\right)=E_{X_{2}}\left[\left\{\text { rhs of }(2.1) \text { for } j=j_{o}, k=k_{o}\right\}-\{\text { rhs of }(2.1) \text { for } j=0, k=0\}\right]
$$

which is a 'marginal' effect relative to $E\left(y_{2}^{j_{o} k_{o}}-y_{2}^{00} \mid X_{2}\right) ; E_{X_{2}}[\cdot]$ means integrating out $X_{2}$ using its population distribution and 'rhs' stands for 'right-hand side'.

Even for two periods, implementing G-algorithm in (2.1) requires finding $E\left(y_{2} \mid d_{1}=\right.$ $\left.j, d_{2}=k, y_{1}, X_{2}\right)$ and $f\left(y_{1} \mid d_{1}=j, X_{2}\right)$ first, and then carrying out the one-dimensional integration, which could be daunting. We will pursue two directions to avoid this computation problem. One is using a binary response, which turns the integral into a simple sum with two terms. The other is adopting linear models, which we will explain shortly.

The G-algorithm in the aforementioned papers of Robins assumes discrete treatments and covariates, and generalizing the G-algorithm to continuous treatments/covariates needs more conditions. Theorem 2 of Gill and Robins (2001) shows that the G-algorithm also works for continuous cases with zero probability of the conditioning event. Gill and Robins (2001) also show that a probability space can be constructed where the counter-factuals live with the observed variables, hence that presupposing counter-factuals is "free" or "harmless" as they do not impose any extra restrictions on the factuals. A review of dynamic treatment effects from the econometric viewpoint can be seen in Abbring and Heckman (2007). 


\subsection{A Simple Linear Model and G-algorithm}

To avoid the computation problem in G-algorithm, we may adopt a linear model, which will also demonstrate well what is actually going on within G-algorithm. Suppose that a simple linear model (omitting $x_{0}$ and $y_{0}$ ) holds:

$$
\begin{aligned}
d_{1} & =\zeta_{1}+x_{1}^{\prime} \zeta_{x}+\varepsilon_{1} \\
y_{1}^{j} & =\beta_{1}+x_{1}^{\prime} \beta_{x}+\beta_{d} j+u_{1} \quad\left(d_{1}=j \text { affects } y_{1}\right) \\
d_{2}^{j} & =\zeta_{1}+x_{2}^{\prime} \zeta_{x}+\zeta_{y} y_{1}^{j}+\varepsilon_{2} \quad\left(y_{1}^{j} \text { affects } d_{2}\right) \\
y_{2}^{j k} & =\beta_{1}+x_{2}^{\prime} \beta_{x}+\beta_{d l a g} j+\beta_{d} k+\beta_{y} y_{1}^{j}+u_{2} \quad\left(d_{1}=j, d_{2}=k, y_{1}^{j} \text { affect } y_{2}\right)
\end{aligned}
$$

where $\zeta$ and $\beta$ are parameters and $\left(\varepsilon_{1}, \varepsilon_{2}, u_{1}, u_{2}\right)$ are mean-zero errors. For this model, the desired effect is

$$
\begin{aligned}
& E\left(y_{2}^{j_{0} k_{o}}-y_{2}^{00}\right) \\
= & E\left\{\beta_{1}+x_{2}^{\prime} \beta_{x}+\beta_{\text {dlag }} j_{o}+\beta_{d} k_{o}+\beta_{y} y_{1}^{j_{o}}+u_{2}-\left(\beta_{1}+x_{2}^{\prime} \beta_{x}+\beta_{y} y_{1}^{0}+u_{2}\right)\right\} \\
= & \beta_{d l a g} j_{o}+\beta_{d} k_{o}+\beta_{y} E\left(y_{1}^{j_{o}}-y_{1}^{0}\right)=\beta_{d l a g} j_{o}+\beta_{d} k_{o}+\beta_{y} \beta_{d} j_{o} .
\end{aligned}
$$

This consists of two parts: the direct effect $\beta_{\text {dlag }} j_{o}+\beta_{d} k_{o}$ of $\left(d_{1}, d_{2}\right)$ on $y_{2}$ and the indirect effect $\beta_{y} \beta_{d} j_{o}$ of $d_{1}$ on $y_{2}$ through $y_{1}$.

Barring some regularity conditions, the following condition is sufficient for NUC1 and NUC2, and thus for G-algorithm:

$$
\begin{array}{lll}
\text { (a) }: & \left(u_{1}, u_{2}\right) \amalg \varepsilon_{1} \mid X_{2} \quad \text { for NUC1 } \\
\text { (b) }: & u_{2} \amalg \varepsilon_{2} \mid\left(\varepsilon_{1}, u_{1}, X_{2}\right) \quad \text { for NUC2. }
\end{array}
$$

In (2.3), given $\left(d_{1}=j, y_{1}^{j}, X_{2}\right), y_{2}^{j k}$ and $d_{2}^{j}$ depend only on $u_{2}$ and $\varepsilon_{2}$, respectively. NUC2 holds thus if (b) holds. Analogously, given $X_{2}, d_{1}$ depends only on $\varepsilon_{1}$, and $y_{2}^{j k}$ depends only on $u_{2}$ and $y_{1}^{j}$ which in turn depends only on $u_{1}$. Hence (a) implies NUC1.

To better understand (2.5), omit ' $\mid X_{2}$ ' for a while and observe the fact:

$$
\left(u_{1}, u_{2}\right) \amalg\left(\varepsilon_{1}, \varepsilon_{2}\right) \Longleftrightarrow\left(u_{1}, u_{2}\right) \amalg \varepsilon_{2} \mid \varepsilon_{1} \text { and }\left(u_{1}, u_{2}\right) \amalg \varepsilon_{1} ;
$$

in $\left(u_{1}, u_{2}\right) \amalg \varepsilon_{2} \mid \varepsilon_{1}$, it looks as if $\varepsilon_{2}$ may be related to $\left(u_{1}, u_{2}\right)$ through $\varepsilon_{1}$, but this is ruled out in $\left(u_{1}, u_{2}\right) \amalg \varepsilon_{1}$. In comparison to this display, in $(2.5)$ with ' $\mid X_{2}$ ' omitted, we get $\left(u_{1}, u_{2}\right) \amalg \varepsilon_{1}$ and $u_{2} \amalg \varepsilon_{2} \mid\left(\varepsilon_{1}, u_{1}\right): \varepsilon_{2}$ may be related to $u_{2}$ through $u_{1}$. Also heteroskedasticity and serial correlations within $\left(\varepsilon_{1}, \varepsilon_{2}\right)$ as well as within $\left(u_{1}, u_{2}\right)$ are allowed. 
A condition stronger than $(2.5)$ is

$$
\left(u_{1}, u_{2}\right) \amalg\left(\varepsilon_{1}, \varepsilon_{2}\right) \mid X_{2} .
$$

This is easier to understand: the selection equation (i.e., the treatment equation) error terms should be unrelated to the outcome equation errors conditional on the covariates - the familiar "static" selection-on-observable condition. The only difference between this and (2.5) is that (2.5)(b) has $u_{1}$ in the conditioning set, which is necessary as $y_{1}^{j}$ gets conditioned on in Galgorithm to allow for the dynamic feedback. Because $y_{1}$ is observed at period 2, (2.5) is also a selection-on-observable condition.

Getting into G-algorithm details with the linear model (2.3), observe

$$
\begin{aligned}
& E\left(y_{2}^{j k} \mid d_{1}=j, d_{2}^{j}=k, y_{1}^{j}, X_{2}\right) \\
= & \beta_{1}+x_{2}^{\prime} \beta_{x}+\beta_{d l a g} j+\beta_{d} k+\beta_{y} y_{1}^{j}+E\left(u_{2} \mid d_{1}=j, d_{2}^{j}=k, y_{1}^{j}, X_{2}\right) \\
= & \beta_{1}+x_{2}^{\prime} \beta_{x}+\beta_{d l a g} j+\beta_{d} k+\beta_{y} y_{1}^{j}+E\left(u_{2} \mid d_{1}=j, y_{1}^{j}, X_{2}\right) \quad \text { using (2.5)(b). }
\end{aligned}
$$

Substitute this into G-algorithm to get

$$
\begin{aligned}
& E\left(y_{2}^{j k} \mid X_{2}\right) \\
= & \int\left\{\beta_{1}+x_{2}^{\prime} \beta_{x}+\beta_{d l a g} j+\beta_{d} k+\beta_{y} y_{1}^{j}+E\left(u_{2} \mid d_{1}=j, y_{1}^{j}, X_{2}\right)\right\} f\left(y_{1}^{j} \mid d_{1}=j, X_{2}\right) \partial y_{1}^{j} \\
= & \beta_{1}+x_{2}^{\prime} \beta_{x}+\beta_{d l a g} j+\beta_{d} k+\beta_{y} E\left(y_{1}^{j} \mid d_{1}=j, X_{2}\right)+E\left(u_{2} \mid d_{1}=j, X_{2}\right)
\end{aligned}
$$

where the integration becomes averaging. Observe

$$
\begin{aligned}
& E\left(y_{1}^{j} \mid d_{1}=j, X_{2}\right)=\beta_{1}+x_{1}^{\prime} \beta_{x}+\beta_{d} j+E\left(u_{1} \mid d_{1}=j, X_{2}\right) \\
& E\left(u_{1} \mid d_{1}=j, X_{2}\right)=0 \text { and } E\left(u_{2} \mid d_{1}=j, X_{2}\right)=0 \quad \text { using }(2.5)(\mathrm{a}) .
\end{aligned}
$$

Substitute these into the preceding display to obtain

$$
\begin{aligned}
& E\left(y_{2}^{j k} \mid X_{2}\right)=\beta_{1}+x_{2}^{\prime} \beta_{x}+\beta_{d l a g} j+\beta_{d} k+\beta_{y}\left(\beta_{1}+x_{1}^{\prime} \beta_{x}+\beta_{d} j\right) \\
\Longrightarrow & E\left(y_{2}^{j k}-y_{0}^{00} \mid X_{2}\right)=\beta_{d l a g} j+\beta_{d} k+\beta_{y} \beta_{d} j=E\left(y_{2}^{j k}-y_{2}^{00}\right) .
\end{aligned}
$$

Comparing the last display with (2.4), we can see that $E\left(y_{2}^{j k}-y_{2}^{00}\right)$ is identified and estimable with G-algorithm. As will be shown later, typical econometric panel dynamic models will miss the effect conveyed by $y_{1}$, i.e., the part due to $E\left(y_{1}^{j} \mid d_{1}=j, X_{2}\right)$. Note that 
(2.5) is sufficient for G-algorithm to work with the linear model; the necessary and sufficient condition can be seen in (2.7) and (2.6):

$$
\begin{aligned}
& \text { (a) : } E\left(u_{1} \mid d_{1}=j, X_{2}\right)=0 \text { and } E\left(u_{2} \mid d_{1}=j, X_{2}\right)=0 \quad \text { for NUC1 } \\
& \text { (b) }: E\left(u_{2} \mid d_{1}=j, d_{2}^{j}=k, y_{1}^{j}, X_{2}\right)=E\left(u_{2} \mid d_{1}=j, y_{1}^{j}, X_{2}\right) \quad \text { for NUC2. }
\end{aligned}
$$

Although we considered the linear model to simplify G-algorithm computation, (2.4) shows that the effect $E\left(y_{2}^{j k}-y_{2}^{00}\right)$ can be found by estimating the $y_{2}^{j k}$ equation in a singlestep because only $\beta_{\text {dlag }}, \beta_{d}$, and $\beta_{y}$ appear in $E\left(y_{2}^{j k}-y_{2}^{00}\right)$; finding $E\left(y_{2} \mid d_{1}=j, d_{2}=k, y_{1}, X_{2}\right)$ and $f\left(y_{1} \mid d_{1}=j, X_{2}\right)$ and then doing the integration in G-algorithm is all unnecessary. The linear model (2.3), however, looks too simple to be realistic. For one thing, it assumes linear effects of $d_{1}$ and $d_{2}$; for another, it assumes a stationary environment. For child TV watching, both restrictions are implausible, and hence we consider a nonstationary model allowing for nonlinear effects of $d_{1}$ and $d_{2}$ next, which will then lead to a two-stage procedure to be used in our empirical analysis.

\subsection{A More General Linear Model and Two-Stage Procedure}

Instead of (2.3), consider

$$
\begin{aligned}
& \left(d_{1} \text { and } d_{2}^{j} \text { equations are the same as in }(2.3)\right), \\
y_{1}^{j}= & \alpha_{1}+x_{1}^{\prime} \alpha_{x}+\alpha_{d 1} j+\alpha_{d 1 q} j^{2}+u_{1} \\
y_{2}^{j k}= & \beta_{1}+x_{2}^{\prime} \beta_{x}+\beta_{d 1} j+\beta_{d 1 q} j^{2}+\beta_{d 2} k+\beta_{d 2 q} k^{2}+\beta_{y} y_{1}^{j}+u_{2} .
\end{aligned}
$$

This generalizes (2.3) for nonlinear treatment effects and non-stationary parameters by introducing quadratic terms in $j$ and $k$ and allowing the parameters of the $y_{1}^{j}$ equation to differ from those of the $y_{2}^{j k}$ equation. The quadratic terms $j^{2}$ and $k^{2}$ are to account for the potential nonlinear effects of TV watching hours: even if TV watching is beneficial, too much TV watching should be harmful. If necessary, various interaction terms can be included in these equations to capture the effect on the subpopulations characterized by the variables interacting with the treatments. Also the squared $y_{1}^{j}$ can be included as well in the $y_{2}^{j k}$ equation. But, for our data with $N \simeq 2180$ and high dimensional $x_{1}$ and $x_{2}$, adding high-order terms can quickly go out of hand. 
The desired effect is

$$
\begin{aligned}
& E\left(y_{2}^{j_{o} k_{o}}-y_{2}^{00}\right) \\
= & E\left\{\beta_{1}+x_{2}^{\prime} \beta_{x}+\beta_{d 1} j_{o}+\beta_{d 1 q} j_{o}^{2}+\beta_{d 2} k_{o}+\beta_{d 2 q} k_{o}^{2}+\beta_{y} y_{1}^{j_{o}}+u_{2}-\left(\beta_{1}+x_{2}^{\prime} \beta_{x}+\beta_{y} y_{1}^{0}+u_{2}\right)\right\} \\
= & \beta_{d 1} j_{o}+\beta_{d 1 q} j_{o}^{2}+\beta_{d 2} k_{o}+\beta_{d 2 q} k_{o}^{2}+\beta_{y} E\left(y_{1}^{j_{o}}-y_{1}^{0}\right) \\
= & \beta_{d 1} j_{o}+\beta_{d 1 q} j_{o}^{2}+\beta_{d 2} k_{o}+\beta_{d 2 q} k_{o}^{2}+\beta_{y}\left(\alpha_{d 1} j_{o}+\alpha_{d 1 q} j_{o}^{2}\right) .
\end{aligned}
$$

Although we can show that G-algorithm identifies this effect, it is not necessary, because we can just estimate the $y_{1}^{j}$ and $y_{2}^{j k}$ equations separately for the $\alpha$ and $\beta$ parameters first, and then combine those estimators to find the desired effect. This two-stage procedure is our main proposal. As in (2.4), the parameters in the $d_{1}$ and $d_{2}^{j}$ equations do not appear in the desired effect, which is why we did not bother with generalizing the $d_{1}$ and $d_{2}^{j}$ equations in (2.9).

Estimating the $\alpha$ and $\beta$ parameters in the linear $y_{1}^{j}$ and $y_{2}^{j k}$ equations brings up a new issue for observational data. For instance, consider the $y_{1}$ equation in the observed random variables:

$$
y_{1}=\alpha_{1}+x_{1}^{\prime} \alpha_{x}+\alpha_{d 1} d_{1}+\alpha_{d 1 q} d_{1}^{2}+u_{1} .
$$

For this to be taken as a data-generating process, we need to specify how $d_{1}$ and $u_{1}$ (and $x_{1}$ ) are related to each other. In the $y_{1}^{j}$ equation, we may assume $E\left(u_{1} \mid x_{1}\right)=0$, but this is moot on how $d_{1}$ is related to $u_{1}-$ no $d_{1}$ in $E\left(u_{1} \mid x_{1}\right)$ is natural as $j$ is a constant in the $y_{1}^{j}$ equation. In contrast, in order to estimate the $\alpha$ parameters in (2.11) with LSE, we need $E\left(u_{1} \mid x_{1}, d_{1}\right)=0$ (or at least zero correlations), which in fact appeared in (2.8) for G-algorithm.

Specifically, getting $E\left(y_{1} \mid x_{1}, d_{1}\right)=\alpha_{1}+x_{1}^{\prime} \alpha_{x}+\alpha_{d 1} d_{1}+\alpha_{d 1 q} d_{1}^{2}$ from

$$
E\left(y_{1}^{j} \mid x_{1}\right)=\alpha_{1}+x_{1}^{\prime} \alpha_{x}+\alpha_{d 1} j+\alpha_{d 1 q} j^{2} \Longleftrightarrow E\left(u_{1} \mid x_{1}\right)=0 \quad \text { in }(2.9)
$$

requires

$$
E\left(y_{1}^{j} \mid d_{1}=j, x_{1}\right)=E\left(y_{1}^{j} \mid x_{1}\right) \Longleftrightarrow E\left(u_{1} \mid d_{1}=j, x_{1}\right)=E\left(u_{1} \mid x_{1}\right)=0 .
$$

Formally, this can be seen in

$$
\begin{aligned}
& E\left(y_{1} \mid d_{1}, x_{1}\right)=\int E\left(y_{1} \mid d_{1}=j, x_{1}\right) \partial 1\left[j \leq d_{1}\right]=\int E\left(y_{1}^{j} \mid d_{1}=j, x_{1}\right) \partial 1\left[j \leq d_{1}\right] \\
= & \int E\left(y_{1}^{j} \mid x_{1}\right) \partial 1\left[j \leq d_{1}\right] \quad(\text { using }(2.12)) \\
= & \int\left(\alpha_{1}+x_{1}^{\prime} \alpha_{x}+\alpha_{d 1} j+\alpha_{d 1 q} j^{2}\right) \partial 1\left[j \leq d_{1}\right]=\alpha_{1}+x_{1}^{\prime} \alpha_{x}+\alpha_{d 1} d_{1}+\alpha_{d 1 q} d_{1}^{2}
\end{aligned}
$$


where $1\left[j \leq d_{1}\right]$ is the distribution for $j$ with unit mass at $j=d_{1}$. The requirement $(2.12)$ i.e., no selection problem from $d_{1}$ - was in fact noted in Lee and Kobayashi (2001) when $d_{1}$ is binary. (2.12) is weaker than (2.8)(a) for G-algorithm in that $x_{2}$ does not appear in the conditioning set.

Doing analogously, $E\left(y_{2} \mid d_{1}, d_{2}, y_{1}, x_{2}\right)=\beta_{1}+x_{2}^{\prime} \beta_{x}+\beta_{d 1} d_{1}+\beta_{d 1 q} d_{1}^{2}+\beta_{d 2} d_{2}+\beta_{d 2 q} d_{2}^{2}+\beta_{y} y_{1}^{j}$ from

$$
E\left(y_{2}^{j k} \mid y_{1}^{j}, x_{2}\right)=\beta_{1}+x_{2}^{\prime} \beta_{x}+\beta_{d 1} j+\beta_{d 1 q} j^{2}+\beta_{d 2} k+\beta_{d 2 q} k^{2}+\beta_{y} y_{1}^{j} \Longleftrightarrow E\left(u_{2} \mid y_{1}^{j}, x_{2}\right)=0
$$

requires

$$
\begin{gathered}
E\left(y_{2}^{j k} \mid d_{1}=j, d_{2}=k, y_{1}^{j}, x_{2}\right)=E\left(y_{2}^{j k} \mid y_{1}^{j}, x_{2}\right) \\
\Longleftrightarrow \quad E\left(u_{2} \mid d_{1}=j, d_{2}=k, y_{1}^{j}, x_{2}\right)=E\left(u_{2} \mid y_{1}^{j}, x_{2}\right)(=0) .
\end{gathered}
$$

(2.13) is weaker than (2.8)(b) for G-algorithm in that $x_{1}$ does not appear in the conditioning set. The separate appearance of $x_{1}$ and $x_{2}$ in (2.12) and (2.13) is due to estimating the period 1 and 2 equations separately in the two-stage procedure, while G-algorithm does the computation together and thus needs $X_{2}$ in the conditioning set. Earlier we noted that the dynamic feedback nature $y_{1} \longrightarrow d_{2}$ makes $d_{2}$ non-randomized even if $d_{1}$ were so. NUC2 and (2.13) show clearly how this problem gets handled: assume that $d_{2}$ is as good as randomized conditioning on $y_{1}^{j}$ (and other variables).

The main advantage of the two-stage procedure is ease of implementation: only two LSE's are needed. Of course, this practicality comes at the cost of specifying the linear functional form for the conditional mean in G-algorithm which is nonparametric in its original form. Other than G-algorithm and our two-stage linear-model-based procedure, other approaches are certainly possible for dynamic treatment effects. For instance, Lechner (2004,2008) propose matching approaches using the 'propensity score' idea in Rosenbaum and Rubin (1983), which is, however, applicable only when the treatment is binary.

\subsection{Covariates Affected by Early Treatment or Response}

Turning back to G-algorithm, there is a complication in G-algorithm in relation to $x_{2}$ being affected by either $y_{1}$ or $d_{1}$, and we address this issue in this subsection. Note that, by construction, $x_{1}$ precedes $d_{1}$ and $y_{1}$, and thus $x_{1}$ cannot be affected by $d_{1}$ or $y_{1}$. 
First, suppose that $d_{1}$ affects $x_{2}$, which in turn affects $y_{2}$ (i.e., $d_{1} \rightarrow x_{2} \rightarrow y_{2}$ ). For example, the period $1 \mathrm{TV}$ hours may affect the physical fitness $x_{2}$ of the child and the fitness may influence $y_{2}$. In this case, the role of $x_{2}$ differs little from that of the early response $y_{1}$. This means that $x_{2}$ affected by $d_{1}$ can be handled in the same way as $y_{1}$ is handled: replace $y_{1}$ in G-algorithm with $\left(y_{1}, x_{2}\right)$ and integrate $\left(y_{1}, x_{2}\right)$ out conditioning, not on $X_{2}$, but on

$$
X_{1} \equiv\left(x_{0}^{\prime}, y_{0}, x_{1}^{\prime}\right)^{\prime}
$$

Specifically, with $x_{2}^{j}$ denoting the potential version for $x_{2}$ when $d_{1}=j$ is exogenously set, we need new NUC's conditioned on $X_{1}$ :

$$
\begin{aligned}
& \text { NUC1' }: \quad y_{2}^{j k} \amalg d_{1} \mid X_{1}, \quad \text { for } j=j_{o}, 0 \text { and } k=k_{o}, 0 \\
& \text { NUC2' }: \quad y_{2}^{j k} \amalg d_{2}^{j} \mid\left(d_{1}=j, y_{1}^{j}, x_{2}^{j}, X_{1}\right), \quad \text { for } j=j_{o}, 0 \text { and } k=k_{o}, 0 .
\end{aligned}
$$

Under this, G-algorithm (2.1) should be modified as

$$
\begin{aligned}
& E\left(y_{2}^{j k} \mid X_{1}\right)=\iint E\left(y_{2} \mid d_{1}=j, d_{2}=k, y_{1}, x_{2}, X_{1}\right) f\left(y_{1}, x_{2} \mid d_{1}=j, X_{1}\right) \partial y_{1} \partial x_{2} \\
= & \iint E\left(y_{2}^{j k} \mid d_{1}=j, d_{2}^{j}=k, y_{1}^{j}, x_{2}^{j}, X_{1}\right) f\left(y_{1}^{j}, x_{2}^{j} \mid d_{1}=j, X_{1}\right) \partial y_{1}^{j} \partial x_{2}^{j} \\
= & \iint E\left(y_{2}^{j k} \mid d_{1}=j, y_{1}^{j}, x_{2}^{j}, X_{1}\right) f\left(y_{1}^{j}, x_{2}^{j} \mid d_{1}=j, X_{1}\right) \partial y_{1}^{j} \partial x_{2}^{j} \quad \text { (NUC2' used) } \\
= & E\left(y_{2}^{j k} \mid d_{1}=j, X_{1}\right) \quad\left(y_{1}^{j} \text { and } x_{2}^{j}\right. \text { integrated out) } \\
= & E\left(y_{2}^{j k} \mid X_{1}\right) \quad \text { (NUC1' used). }
\end{aligned}
$$

We get $E\left(y_{2}^{j_{o} k_{o}}-y_{2}^{00} \mid X_{1}\right)$, not $E\left(y_{2}^{j_{o} k_{o}}-y_{2}^{00} \mid X_{2}\right)$, from which $E\left(y_{2}^{j_{o} k_{o}}-y_{2}^{00}\right)$ can be obtained by integrating out $X_{1}$.. In our data, we do not have period-2 covariates for $d_{1} \rightarrow x_{2} \rightarrow y_{2}$, and thus this generalization of G-algorithm will not be needed.

Second, suppose that $y_{1}$ affects $x_{2}$, which in turn affects $y_{2}$ (i.e., $y_{1} \rightarrow x_{2} \rightarrow y_{2}$ ). For instance, if the period-1 test score is poor (good), the parents may take some disciplinary (rewarding) measure, such as grounding the child (taking the child out to a ballpark), and this can affect the period-2 test score. As in the preceding case, this requires $x_{2}^{j}$ equation, and the modified G-algorithm (2.15) still works. But the problem is that there might be too many such variables in our data, which makes G-algorithm non-operational. We will assume that the effects of such variables are negligible. As the disciplinary/rewarding measure example suggests, those variables are of temporary nature rather than persistent, and if there are any effects, the effects would be small. 
To better see the problems we will encounter if we try to account for all effects in the latter case $y_{1} \rightarrow x_{2} \rightarrow y_{2}$, observe that $E\left(y_{2}^{j_{o} k_{o}}-y_{2}^{00}\right)$ in (2.4) consists of three effects shown by three arrows pointing to $y_{2}$ in Figure 2; the part $y_{1} \rightarrow d_{2}$ in Figure 1 is 'blocked' as $E\left(y_{2}^{j_{o} k_{o}}-y_{2}^{00}\right)$ is the 'intervention' effect of setting $d_{1}=j_{o}$ and $d_{2}=k_{o}$ exogenously given the observables. In Figure 3 with $y_{1} \rightarrow x_{2} \rightarrow y_{2}$ added, now there are four arrows pointing to $y_{2}$. G-algorithm can accommodate this with (2.15), but if the dimension of $x_{2}$ is large, then G-algorithm is not operational. Our two-stage procedure can also accommodate the added arrow effect, but this will make (2.10) too complicated by adding too many terms.

Figure 2

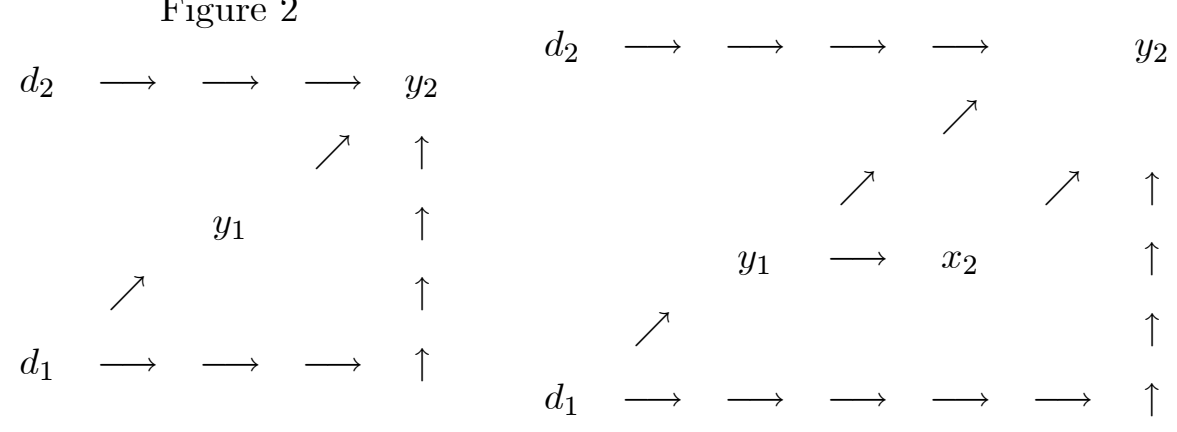

In principle, there is no compelling reason why we should exclude the effect from $d_{1} \rightarrow$ $y_{1} \rightarrow x_{2} \rightarrow y_{2}$. But as argued above, this effect seems negligible in our application, as one can immediately see, after examining the list of home inputs at ages 6-7 and 8-9 in the appendix which are mostly family routines represented by binary variables, that these intermediate covariates are not likely to change responding to earlier test outcomes. For example, parents may reduce the number of trips to museums after seeing a bad test score, but so long as they take the child to museums at least several times a year, the value of the binary variable does not change according to the way the museum visit variables are constructed. As in any treatment effect analysis, we will never be able to account for all effects as "a butterfly's flutter in one side of the Pacific may cause a hurricane on the other side". It is either the foreseeable negligible magnitude or the technical difficulty of gauging the effect that keeps us from pursuing all effects.

\subsection{G-algorithm with Binary Responses}

We proposed a linear model approach to G-algorithm to alleviate the implementation problem of the G-algorithm in (2.1). If many high-order terms should appear (particularly 
$y_{1}^{2}, y_{1}^{3}, \ldots$ in the $y_{2}$ equation), however, then even the linear model approach becomes cumbersome. The G-algorithm can be implemented with much ease if $y$ is binary-no need for $y_{1}^{2}, y_{1}^{3}, \ldots$ any more - in which case the G-algorithm becomes a sum of two terms:

$$
\begin{gathered}
E\left(y_{2}^{j k} \mid y_{0}, X_{2}\right)=P\left(y_{2}=1 \mid d_{1}=j, d_{2}=k, y_{1}=0, X_{2}\right) \cdot P\left(y_{1}=0 \mid d_{1}=j, X_{2}\right) \\
+P\left(y_{2}=1 \mid d_{1}=j, d_{2}=k, y_{1}=1, X_{2}\right) \cdot P\left(y_{1}=1 \mid d_{1}=j, X_{2}\right) .
\end{gathered}
$$

Other than for avoiding $y_{1}^{2}, y_{1}^{3}, \ldots$, binary response may be less susceptible to recall errors; in our data, the TV watching hours may be subject to recall errors.

For instance, apply probit (or logit) to $y_{2}$ on $d_{1}, d_{2}, y_{1}$ and $X_{2}$ to obtain the two probit probabilities for $y_{2}=1$ in $(2.16)$ :

$$
\Phi\left(\psi_{1}+\psi_{d 1} d_{1}+\psi_{d 2} d_{2}+\psi_{y 1} y_{1}+\psi_{x}^{\prime} X_{2}\right)
$$

where the $\psi$-parameters are to be estimated. Also apply probit (or logit) to $y_{1}$ on $d_{1}$ and $X_{2}$ to get the probit probabilities for $y_{1}=1$ (and $\left.y_{1}=0\right)$ :

$$
\Phi\left(\eta_{1}+\eta_{d 1} d_{1}+\eta_{x}^{\prime} X_{2}\right)
$$

where the $\eta$-parameters are to be estimated. Substituting these into $(2.16)$ will do. This version will be applied to our data as well.

\section{Dynamic Panel Data Model Estimators}

Facing the task of finding the effect of $\left(d_{1}, d_{2}\right)$ on $y_{2}$ when $d_{1}$ can influence $y_{2}$ through $y_{1}$ as well, the usual econometric panel data approach would be using a dynamic panel data model. Various dynamic panel-data models are conceivable, but a comprehensive model is

$$
y_{2}=\beta_{1}+x_{1}^{\prime} \beta_{x 1}+x_{2}^{\prime} \beta_{x 2}+\beta_{d 1} d_{1}+\beta_{d 1 q} d_{1}^{2}+\beta_{d 2} d_{2}+\beta_{d 2 q} d_{2}^{2}+\beta_{y 0} y_{0}+\beta_{y 1} y_{1}+v_{2}
$$

where $v_{2}$ is an error term. But this model cannot deliver the desired effect $E\left(y_{2}^{j_{o} k_{o}}-y_{2}^{00}\right)$ in (2.10) because the indirect effect $\beta_{y}\left(\alpha_{d 1} j_{o}+\alpha_{d 1 q} j_{o}^{2}\right)$ of $d_{1}$ on $y_{2}$ through $y_{1}$ is missed. This, which is due to controlling $y_{1}$, is the main disadvantage of the usual dynamic panel-data approach. Our proposed two-stage method is a simple adjustment of this: estimate the $y_{1}$ equation as well, and construct (2.10) adding the missed indirect effect $\beta_{y}\left(\alpha_{d 1} j_{o}+\alpha_{d 1 q} j_{o}^{2}\right)$.

If we do not control $y_{1}$ in (3.1) to avoid the problem of missing the indirect effect, then the effect of $d_{2}$ on $y_{2}$ may get distorted because the omitted $y_{1}$ becomes a 'common factor' for 
$d_{2}$ and $y_{2}$, causing an omitted variable bias. That is, even if there is no true effect of $d_{2}$ on $y_{2}$, we may find a spurious effect of $d_{2}$ due to not controlling $y_{1}$. This dilemma is fundamental to dynamic treatment effect analysis under feedback: control $y_{1}$ to miss the indirect effect, or not control $y_{1}$ to incur an omitted variable bias.

For our empirical analysis, we will use and compare a number of estimators. First, LSE to $(3.1)$, in which the test for " $H_{o}$ : all coefficients for the treatments are zero" amounts to 'Granger-noncausality test' (Granger, 1969,1980). Second, 'fixed-effect estimator' to the model (with $\Delta y_{i t} \equiv y_{i t}-y_{i, t-1}$ and $\Delta d_{i t}^{2} \equiv d_{i t}^{2}-d_{i, t-1}^{2}$ )

$$
\begin{gathered}
y_{i t}=\alpha_{t}+\alpha_{d} d_{i t}+\alpha_{d q} d_{i t}^{2}+x_{i t}^{\prime} \alpha_{x t}+\delta_{i}+v_{i t} \\
\Longrightarrow \quad \Delta y_{i 2}=\alpha_{2}-\alpha_{1}+\alpha_{d} \Delta d_{i 2}+\alpha_{d q} \Delta d_{i 2}^{2}+x_{i 2}^{\prime} \alpha_{x 2}-x_{i 1}^{\prime} \alpha_{x 1}+\Delta v_{i 2} .
\end{gathered}
$$

Third, in this differenced model, the lagged variables in $\Delta y_{i 2}, \Delta d_{i 2}$, and $\Delta d_{i 2}^{2}$ appear with the restricted coefficient -1 , and if we remove these restrictions, we get (3.1) (without $y_{0}$ ); instrumental variable estimator (IVE) to (3.1) is our third estimator that is the most "endogeneityconscious" estimator. Fourth, LSE to the observed version of (2.9):

$$
\begin{aligned}
& y_{1}=\alpha_{1}+x_{1}^{\prime} \alpha_{x}+\alpha_{d 1} d_{1}+\alpha_{d 1 q} d_{1}^{2}+u_{1} \\
& y_{2}=\beta_{1}+x_{2}^{\prime} \beta_{x 2}+\beta_{d 1} d_{1}+\beta_{d 1 q} d_{1}^{2}+\beta_{d 2} d_{2}+\beta_{d 2 q} d_{2}^{2}+\beta_{y} y_{1}+u_{2}
\end{aligned}
$$

this is our main two-stage estimator. Fifth, G-algorithm to binary response (2.16) after transforming $y_{t}$ to the binary response taking 0 or 1 depending on whether $y_{t}$ is smaller than its mean or not.

As for Granger-causality, we consider this for two reasons. Firstly, although we adopt the 'counter-factual causality' framework as explained in the preceding section, dissenting views on causality are also strong as can be seen in Holland (1986) and Dawid (2000). Because Granger-causality is widely used in time-series econometrics with its panel version in HoltzEakin et al. $(1988,1989)$, it seems sensible to consider a model that can test for Grangercausality. Secondly, although Granger-causality does not imply nor is implied by the counterfactual causality in general, Robins et al. (1999) show that the two concepts do agree in some cases; see also Lechner (2006) further on the comparison of the counter-factual and Grangertype causalities. In our framework, the magnitude of the $\left(d_{1}, d_{2}\right)$ effect estimated in (3.1) is not meaningful as (3.1) misses the indirect effect as already pointed out, but Grangernoncausality of $\left(d_{1}, d_{2}\right)$ is meaningful under the stationary environment of the same $\alpha$ and 
$\beta$ parameters, which can be seen in (2.4):

$$
E\left(y_{2}^{j_{o} k_{o}}-y_{2}^{00}\right)=\beta_{d l a g} j_{o}+\beta_{d} k_{o}+\beta_{y} \beta_{d} j_{o}=0 \quad \text { if } \beta_{\text {dlag }}=\beta_{d}=0
$$

That is, the missed indirect effect is also zero when the direct effect is zero thanks to the "stationarity" assumption that $\beta_{d}$ appears in the $y_{1}^{j}$ equation as well as in the $y_{2}^{j k}$ equation in $(2.3)$.

Turning to fixed-effect estimator, it is one of the most popular estimator in panel data, which is one reason why we apply this to our data. As well known, an important source of endogeneity in a panel data model is the 'unobserved unit-specific effect $\delta_{i}$ ' when $v_{i t}$ is redefined as $\delta_{i}+v_{i t}$. The endogeneity is then removed by differencing the model as in (3.2). To further remove any remaining endogeneity, IVE can be applied to the differenced model, but we chose to apply IVE to (3.1) for even more generality because (3.1) includes the differenced model as a sub-model.

Notice that removing $\delta_{i}$ by first-differencing requires a kind of stationarity that $\delta_{i}$ enters both equations with the same "slope". If one believes that the TV effect is stationary being the same at all ages, then the same slope specification for $\delta_{i}$ may be adopted and the differencing may be the way to go. The effect found there would be applicable to all ages, leading to a "long-run effect", despite that the NUC's hold only at two periods. But this scenario seems overly optimistic. Rather, the TV effects and the $\delta_{i}$ slopes are all likely to be non-stationary. We thus allow the nonstationary aspect in our two-stage procedure, and this should matter much.

In econometrics, most "energy" seems to have been spent on dealing with endogeneity, in contrast to the statistical literature for G-algorithm where accounting for the full effect is given more priority while the endogeneity problems are "swept under the rug" with NUC conditions. It is thus interesting to see how the dynamic panel-data (IVE) econometric approaches with emphasis on endogeneity differ from G-algorithm-based approaches with emphasis on getting the full effect.

As for instruments, Angrist and Krueger (2001) show an ingenious list of instruments in various studies, but having that type of instruments is not always possible. Rather, in typical panel data, it is unavoidable that one finds instruments within the data-namely, lagged regressors. Because (3.1) involves already $y_{1}, d_{2}, d_{1}, x_{2}$, and $x_{1}$, the only source left for instruments for endogenous regressors is $x_{0}$, and $x_{0}$ will be the source for our instruments. 
As $x_{0}$ is not an "ideal" instrument, this part of the empirical analysis should be taken with a grain of salt.

Related to endogeneity, we point out that the identification of the desired effect $E\left(y_{2}^{j_{o} k_{o}}\right.$ $\left.y_{2}^{00}\right)$ as in (2.10) is a separate matter from specifying the data generating process and getting concerned about the ensuing endogeneity there. In dynamic panel-data models, often the interest falls on the initial condition $y_{0}$ and the unobserved unit-specific effect $\delta$. This is relevant to estimating the model with observed data, but not to specifying the desired effect. To see this, observe that no matter what $y_{0}$ and $\delta$ might be, so long as they do not interact with the treatments, they get cancelled out in the difference $y_{2}^{j_{o} k_{o}}-y_{2}^{00}$, and thus have no impact on the desired effect.

\section{Data Description}

The NLSY79 child sample contains rich information on children born to the women respondents of the NLSY79. Starting from 1986, a set of questionnaires was developed to collect information about the cognitive, social, and behavioral development of children. The collected variables include detailed home inputs as well as family backgrounds and school inputs. Based on children surveyed from 1986 to 1998, we constructed a longitudinal sample of about 2600 children with no missing values in Peabody Individual Achievement Test (PIAT) math and reading scores at ages 8-9 $\left(y_{2}\right)$ and TV watching hours at ages 6-7 and 8-9 $\left(d_{1}, d_{2}\right)$. The first period is ages 6-7, and the second period is ages 8-9; the ages 4-5 are then used as the base period (period 0). When we include PIAT scores at ages 6-7 $\left(y_{1}\right)$, the available sample size remains almost the same; it gets smaller when PIAT scores at ages 4-5 $\left(y_{0}\right)$ are included, since only children aged 5 and above are tested with PIAT. The change of sample size is shown at the bottom of Table 1. The missing data for PIAT scores at ages 4-5 are due to the simple fact that many children of ages 4-5 are below age 5 and hence not eligible for the tests.

The relevant questions on TV watching ask a mother how many hours her child watches TV on a typical weekday and weekend day. While examining the data, we found that some answers do not seem valid: the reported hours sometimes go well beyond 24 hours. This may be due to a confusion between a daily measure and a weekly measure of TV watching hours. Thus we excluded children reportedly spending more than ten hours watching TV on 
a typical day at any age. This left us with a sample of 2180 children, based on which all of our empirical analyses were conducted. The summary statistics of some variables in this sample are listed in Table 1, and the complete set of variables is provided in the Appendix. Since school inputs were not available for children above five years old before 1992, there are many missing entries in school inputs.

PIAT Math score offers a wide-range measure of achievement in mathematics, and PIAT Reading Recognition score assesses their attained reading knowledge. Both are among the most widely used assessments of academic achievements. The norming sample has mean 100 and standard deviation (SD) 15 for both math and reading scores; these were normed against the standards based on a national sample of children in the United States in 1968. The PIAT math in our sample has mean 102.2 and SD 13.9 around age nine, and the PIAT reading score has mean 105 and SD 14.6.

In the sample, the average child spends 3.5 hours per day watching TV at ages 8-9 and 3.2 hours at ages $6-7$. Specifically, around $60 \%$ of children aged 8-9 watch more than 2 hours TV per weekday, and $21 \%$ of them more than 4 hours; on weekends, they watch TV for longer hours: around $72 \%$ exceeding 2 hours and 35\% exceeding 4 hours. These patterns are quite similar to those at ages 6-7, though younger children usually watch less TV. We choose to use a measure of daily TV viewing hours in the form

$$
\frac{1}{7}\{5 \times(\text { average weekday watching hours })+2 \times(\text { average weekend-day watching hours })\} .
$$

White children on average watch about one hour less TV per day at both ages 6-7 and 8-9 than the others, and their PIAT scores are 8.8 points higher in math and 6.4 points higher in reading. There is virtually no difference between boys and girls in TV watching hours and PIAT scores, while firstborns watch about half an hour less than the others and get higher math and reading scores. A child with ten or more child-books at home watches around 1.2 hours less TV at ages 8-9 and have much higher scores (11.2 points higher in math and 12.1 in reading) than those with fewer books. Similarly, children whose mothers read to them frequently (at least three times per week) and whose parents discuss TV programs with them spend less time in watching TV than others and get higher grades. In general, TV watching times are significantly and negatively correlated with other activities such as going to museums and theaters.

Public school children watch about one hour more TV on a daily basis at ages 6-7 and 
8-9 than those in private schools, and their math and reading scores are lower. The perceived quality of detailed school inputs (including the skills of the principal and teachers, how much teachers care about the students, whether parents are given enough information and opportunity to participate in school affairs, the safety and order of the school, and whether moral teaching is offered), however, do not seem to affect much TV watching time, although they are positively associated with both math and reading scores. The correlation between TV watching hours and time spent on math homework or reading and writing assignments is quite weak and sometimes positive, which is possibly due to multitasking where many children watch TV while doing homework (Rideout et al. 2005).

Children with mothers having 16 or more years of schooling watch about one hour less TV. Similarly, children whose mothers have above average AFQT scores watch 1.4 hours less TV at ages 8-9 and around 1.2 hours less at ages 6-7, and their PIAT scores are much higher (10 points higher in math and 9 in reading). In summary, children with high quality home inputs and better educated mothers watch much less TV, while school inputs have relatively less influence.

A salient feature in Table 1 is that less time spent viewing TV is almost always associated with higher math and reading scores. The potentially harmful effects of TV watching, however, may be over-estimated if detailed home inputs are not controlled, since a child watching more TV also lacks important home inputs. The strength of our data is that a rich set of home inputs from birth up to age nine as well as key family background variables are available; for some children, there are also many detailed school inputs available. This would greatly reduce potential biases due to omitted variables. Most home and school input variables were categorical with multiple levels, which were converted to dummy variables according to sample medians. The age-specific Home Observation Measurement of the Environment variable (HOME), which is a simple summation of the dichotomized individual input item scores, is often used in child development research as an aggregate quality indicator of home environment. The completion rates of HOME, however, are in general very low for children under age four, which causes many missing values. Whenever possible, HOME is included as a control in addition to detailed home inputs.

In discussing the dynamic treatment effects, we desire the time sequence $x_{t} \longrightarrow d_{t} \longrightarrow y_{t}$ in each period so that $x_{t}$ works as the time- $t$ baseline covariates which affect $d_{t}$ and possibly $y_{t}$, and then the treatment $d_{t}$ affects $y_{t}$. In our data, this temporal order is plausible for a couple 
of reasons. First, $y_{t}$ is measured on the interview day, which means that $x_{t}$ and $d_{t}$ precede $y_{t}$. Second, many family characteristics in $x_{t}$ are likely to be determined independently of $d_{t}$. Third, overall, TV watching hours tend to be the "residual" usage of time, and thus is unlikely to influence the other time-consuming activities, although we cannot completely rule out TV watching taking precedence over the other activities.

The availability of a rich set of control variables in out data is crucial for the application of G-estimation, which relies on the credibility of the 'no unobserved confounder' assumption. As listed in the Appendix, our control variables contain four groups: (1) a child's demographic information including race, sex, and birth order; (2) home inputs at different ages 4-5, 6-7, and 8-9, which cover many aspects of a child's life at home, such as the numbers of child books at home, how often the mother reads to the child, how often the child is taken to museum, performance, outdoor activities, meeting with relatives, have having meals with parents, etc.; (3) school inputs at ages 6-7 and 8-9, including the number of hours spent on math and writing homework, whether the school is public or private, the mother's rating of school quality such as the skills of the principal and teachers, and the safety and order of the school; (4) family backgrounds including the mother's AFQT score, highest grade, marriage status, age at the child's birth, whether the child was breast-fed, and family income. These variables constitute a highly comprehensive set of controls for our purpose of finding the dynamic effects of TV viewing on math and reading scores for children at ages 8-9. After controlling them, it is not easy to think of any important unobserved confounders that may affect both TV viewing time and math and reading scores. That said, a better data set should also include more information about the child's father, such as his AFQT score and education level, and more objective variables on school quality.

\section{$5 \quad$ Empirical Results}

\subsection{Granger Causality}

Table 2 presents results for Granger causality for model (3.1). The various specifications differ mainly in the control variables used. In the first column 'OLS' of both math and reading score regressions, the earlier scores $y_{1}$ at ages 6-7 and $y_{0}$ at ages 4-5 are used as well as the basic group of controls which include the child's race, sex, birth order, home inputs 
at ages 6-7 and 8-9, and family backgrounds variables (mother's AFQT score, her age at the child birth, whether the child was breast-fed, her marriage status, her highest grade, and family income). The sample sizes drop much when the school inputs at ages 6-7 and 8-9 are controlled in the second column 'OLS(S)'. Home inputs at ages 4-5 are further added in the third column 'OLS(SH)', which contains the most comprehensive set of controls and hence the smallest sample size.

For math scores at ages 8-9, TV watching hours at ages 6-7 and 8-9 are jointly significant across these specifications with $p$-values at least 0.07 , though the coefficients of individual TV watching variables are sometimes not significant; TV hours at ages 6-7 have positive and concave effects, while those at ages 8-9 have negative and convex effects. For reading scores at ages 8-9, the joint significant levels of TV watching hours are overall lower than those for math except in the most comprehensive specification 'OLS(SH)', where TV hours at ages 6-7 and 8-9 are jointly significant with p-value 0.009 . The effects of TV watching hours at both age periods seem to have positive and concave effects.

To compare later with the other tables, the mean differences in PIAT scores between different TV watching hours at ages 6-7 and 8-9 are listed in the lower half of Table 2. More time spent on watching TV (up to 6 hours daily) is associated with higher math scores, while the TV effects on reading scores seem positive and concave with the best outcome achieved at 3 hours in 'OLS(S)' and 'OLS(SH)'. These results, however, are not significantly different from zero. As emphasized earlier, these mean differences capture only the direct effects of TV watching since the lagged PIAT scores are controlled.

In summary, there exists clear evidence of Granger causality of TV watching at ages 6-7 and 8-9 on PIAT math and reading scores at ages 8-9. The effects of TV watching seem to differ in both magnitude and sign for math versus reading scores. With the Granger-causality establishing that at least there are direct effects of TV watching on the scores, the orderly thing to do is proceeding further to obtain the full dynamic effects of TV watching including the indirect effect that is missed in Granger-causality. But before that, in the next subsection, we will present some estimation results for typical econometric panel-data methods.

\subsection{Fixed Effect with IV}

In Table 3, columns 'FE(IV)' present the results based on model (3.1) where home inputs at ages 4-5 are used as instruments for the current home inputs at ages 8-9; as in Table 2, the 
squared treatment variables are used. As noted already, (3.2) may be regarded as (3.1) with the restriction that the lagged variables have the opposite signs and the same magnitude. This proposition is supported partly by the different signs of $d_{1}$ and $d_{2}$ and their squared versions in Tables 2 and 3.

Table 3 allows for endogeneity of the current home inputs, which are the G2 group of variables in the appendix, including daily TV viewing hours, whether the child has more than 10 books, whether the child's mother reads to him/her at least 3 times a week, whether the child reads everyday for enjoyment, whether the child's family encourages hobbies, whether the child is taken to museum and performance for at least several times a year, whether the child family gets together with relatives or friends at least two or three times a month, whether the child does outdoor activities with father at least once a week, whether the child eats with parents at least once a day, and whether parents discuss television programs with child. The instruments for these variables are the home inputs at ages 4-5, which are listed in the appendix as the G4 group of variables, and are very similar to the home inputs at ages 8-9.

Consistent with the OLS specification for Table 2, TV hours at ages 6-7 have positive and concave effects, while those at ages 8-9 have negative and convex effects for math score; the coefficients of individual TV watching variables, however, are insignificant due to the low precision in estimation. But, in contrast to the OLS results in Table 2, spending more time watching TV at ages 6-7 and 8-9 is overall associated with lower math scores in ' $\mathrm{FE}(\mathrm{IV})$ ', as shown at the lower half of the table in the same column. This is due to the much larger negative marginal effect of the current TV hours (-7.90 in 'FE(IV)' versus -2.68 in 'OLS(SH)' in Table 2) when they are instrumented by TV hours and other home inputs at ages 4-5. Similar results apply to reading score, where the different coefficients and effects of TV hours at ages 8-9 do not amount to significant differences from the OLS specification (Hausman test used for this).

Columns 'DF' and 'DF (S)' are based on the first-difference model (3.2); they differ only in terms of control variables, where school inputs at ages 6-7 and 8-9 are further controlled in 'DF (S)'. For PIAT math scores at ages 8-9, TV watching time at ages 8-9 has a negative and convex effect on math scores under both specifications, which leads to an overall negative effect between TV hours and math scores as shown in the lower half of the table. For reading scores at ages 8-9, TV watching time at ages 8-9 has a positive and concave effect under 
both specifications, where 3-hour TV watching achieves the best outcome in 'DF' while 4hour is best when school inputs are controlled under 'DF (S)'. These estimated TV effects, however, are statistically insignificant for both math and reading scores. There is a notable, but statistically insignificant, difference for math scores between the negative TV effects in the first-difference results and the positive effects under various OLS specifications in Table 2 , suggesting that the unobserved child-specific factor may matter more for math scores than for reading scores.

The overall results of these fixed-effect models with IVE are not significantly different from the OLS specifications for Table 2, possibly because many detailed home inputs and family backgrounds are already controlled. This finding suggests that we may proceed to G-estimation and the two-stage procedure without worrying too much about the potential biases caused by the unobserved child-specific fixed effect or the endogeneity of the current inputs.

\subsection{Two-Stage Procedure with Linear Models}

Table 4 presents results for the two-stage procedure with the linear model (3.3). The two specifications 'OLS' and 'OLS(S)' differ only in their control variables, where the current school inputs are included in 'OLS(S)' for both periods. Under both specifications, the effects of TV watching at ages 6-7 on scores at ages 6-7 are negative and convex for math scores and just negative for reading scores. But, as shown in the lower half of Table 4 , the overall effects of TV watching across ages 6-7 and 8-9 on math and reading scores at ages 8-9 in 'OLS(S)' are negative for math scores and concave for reading scores, where the best outcome is achieved at two hours in column 'TSE(S)' where the school inputs are controlled (and at six hours in column 'TSE'), where TSE stands for 'two-stage estimator'. Overall, however, the magnitudes of most TV effects are quite small and statistically insignificant. For example, based on estimates in columns TSE(S), watching two hours TV per day during ages 6-7 and 8-9 reduces the math score at ages 8-9 by $4 \%$ of one standard deviation, but increases one's reading score at ages $8-9$ by $3 \%$ of one standard deviation, compared with not watching TV at all.

To get a sense of the relative importance of the indirect effect of TV watching at ages 6-7 on the math and reading scores two years later, we did some calculation based on the estimates in columns 'OLS(S)'. For math score, compared with not watching TV at all, the 
effect of one-hour TV watching at ages 6-7 on the math score at ages 6-7 is $(-.74+.01)=-.73$, which leads to an indirect effect on the math score at ages $8-9,-.73 * . .64=-.47$, while its direct effect is $(-.06+.02)=-.04$. The effect of one-hour TV viewing at ages $8-9$ is $(.20+.002)=.202$. So the indirect effect of earlier TV watching at ages $6-7$ (which is -.47 ) is almost three times the total direct effect of TV watching at both ages 6-7 and 8-9 (which is ..162 =.202-.04), and makes the total effect of one-hour TV watching at ages 6-7 and 8-9 negative (-.30 as reported at the first row in column 'TSE $(\mathrm{S})$ ' for math), despite the positive effect of current TV viewing at ages 8-9.

Doing analogously, based on the estimates in column 'OLS(S)' for reading score, the mean difference between the effects of 6-hour and 2-hour TV viewing at ages 6-7 and 8-9 on reading scores at ages 8-9 (which is -1.78 as reported at the last row in column 'TSE(S)' for reading) can be decomposed into three components: the indirect effect of TV viewing time at ages $6-7$ is $[(-.49 * 6-.01 * 36)-(-.49 * 2-.01 * 4)] * . .78=-1.78$, the direct effect of

$d_{1}$ and $d_{1}^{2}$ is $(-.47 * 6+.02 * 36)-(-.47 * 2+.02 * 4)=-1.24$, while the direct effect of $d_{2}$ and $d_{2}^{2}$ is $(1.27 * 6-.12 * 36)-(1.27 * 2-.12 * 4)=1.24$. Again, the indirect effect of TV viewing at ages 6-7 dominates the total direct effect of TV viewing at ages 6-7 and 8-9, and outweighs the positive effect of the current TV watching.

\subsection{G-algorithm with Discrete Responses}

The insignificance of the total TV effects in Table 4 might be due to measurement errors, since few parents can recall with much accuracy the exact hours their children watch TV every day. It is quite plausible, however, most parents know the time range their kids spend in front of TV. This prompts us to apply the simplified G-estimation with discrete responses, where we convert the average daily TV watching hours to three dummy variables: High TV if a child watches TV for more than 4 hours per day, Middle $T V$ if between 2 and 4 hours, and Low $T V$ if less than or equal to 2 hours. The three levels are done mainly to capture the possible concavity feature of TV watching effects. We also convert PIAT math and reading scores to dummy variables which take on 1 if higher than the sample mean and 0 otherwise. The basic set of controls includes detailed home inputs at ages 6-7 and 8-9, home environment indicators at ages 4-5, child demographic information and family backgrounds variables, while detailed home inputs at ages 4-5 are further added in columns labeled 'Probit(H)' and 'G-est.(H)'.

The probit results are shown in the upper part of Table 5, where the entries are the 
estimated marginal effects calculated at the sample means of the control variables ( i.e., the derivatives of $P\left(y_{2}=1 \mid \cdots\right)$ evaluated at the sample averages). For math scores at ages 8-9 and 6-7, none of the TV dummies is significant. For reading score at ages 8-9, the coefficient of High TV at ages 6-7 is insignificantly negative in column 'Probit', while that at ages 8-9 is significantly positive in 'Probit $(\mathrm{H})$ '. There seems to be some nonlinear effects, but most individual estimates are insignificant.

The G-estimation using the above probit regressions are presented in the lower half of Table 5. Compared to the benchmark of watching TV less than or equal to 2 hours per day at both ages 6-7 and 8-9, the total effects of watching TV for more than 4 hours at both ages are negative and significant for both math and reading scores at ages 8-9 over different models. Specifically, a child with High TV at ages 6-7 and 8-9 reduces his/her probability of having a higher-than-average math score by $18 \%$ in the first column 'G-est.' and $23 \%$ in the second column 'G-est.(H)'; the corresponding probability for reading scores is lowered by $21 \%$ and $23 \%$ respectively for the two specifications. Since the SD of having a higherthan-average score is around .50, these percentage reductions amount to almost half the SD. Middle level TV hours (between 2 and 4 hours per day) at ages 6-7 and 8-9 also have negative and significant effects on math and reading scores, though their magnitudes are smaller than those of High TV: the probability of having a higher-than-average PIAT score is reduced by 16\%-18\% for math and $13 \%-14 \%$ for reading.

It seems that TV watching at ages 6-7 has much larger negative effects on both math and reading scores at ages 8-9 than TV watching at ages 8-9. For example, in the last two rows of Table 5, the results in the first column 'G-est.' show that, watching more than 4 hours TV daily at ages 6-7 reduces the probability of having a higher-than-average math score by $23 \%$, while watching between 2 and 4 hours TV daily reduces it by $19 \%$ even when the TV watching time is less than or equal to 2 hours per day at ages 8-9; the corresponding numbers (unreported in Table 5) are $18 \%$ and $16 \%$ respectively when the TV watching hours at ages 8-9 are High and Middle instead. These results imply that watching more TV at ages 8-9 actually does much less harm compared to the effects of TV hours two years earlier. More or less the same statements can be made for reading scores.

\section{Conclusions}


When multiple treatments are given over time with a feedback of interim responses affecting some future treatments, finding the total effect of all treatments on the final response measured at the end is difficult. The fundamental dilemma is that, if the interim responses are controlled as in the usual dynamic models, then the indirect effect from the earlier treatments on the final response through the interim responses is missed; if not controlled, the interim responses become unobserved confounders for the direct effect of the affected treatments on the final response. Despite this difficulty, the G-estimation (or G-algorithm) originally developed in biostatistics can identify the total effect, unlike the usual OLS or IVE applied to dynamic models with lagged responses on the right-hand side.

This paper reviewed G-estimation, developed a two-stage procedure, and applied a discretized version of G-algorithm as well as the two-stage procedure to an important issue: the effect of watching TV on child cognitive development measured by math and reading scores. For math score, the two-stage results indicated that watching TV for any amount of time during ages 6-7 and 8-9 has a negative total effect at ages 8-9 where the negative effects of TV watching at younger ages 6-7 are much larger, which was not expected beforehand. Furthermore, results from these estimators as well as typical panel-data econometric approaches using continuous response variables led to a coherent evidence that around two hours TV watching per day seems to bring the best reading scores than too much or too little TV hours, while the effects of TV watching on math scores are usually negative.

These findings collectively explain why the effect of TV watching on child cognitive development has been controversial: the effect varies depending on the TV watching age, and it is nonlinear with changing signs. Also its magnitude is small, suggesting that TV effect may not matter that much after all. The total effect feature found by our dynamic framework provided a richer "story", taking only part of which would convey misleading messages.

\section{REFERENCES}

Abbring JH, Heckman JJ. 2007. Econometric evaluation of social programs, part III: distributional treatment effects, dynamic treatment effects, dynamic discrete choice, and 
general equilibrium policy evaluation. In Handbook of Econometrics 6B, Heckman JJ, Leamer EE (eds). North-Holland.

Anderson DR. 2005. Television and very young children. American Behavioral Scientist 48: $505-522$.

Angrist JD, Krueger AB. 2001. Instrumental variables and the search for identification: from supply and demand to natural experiments. Journal of Economic Perspectives 15: $69-85$.

Chernin AR, Linebarger DL. 2005. The relationship between children's television viewing and academic performance. Archives of Pediatrics \& Adolescent Medicine 159: 687-689.

Dawid AP. 2000. Causal inference without counterfactuals. Journal of the American Statistical Association 95: 407-424.

Gentzkow M, Shapiro JM. 2008. Preschool television viewing and adolescent test scores: historical evidence from the Coleman study. Quarterly Journal of Economics 123: 279-323.

Gill RD, Robins JM. 2001. Causal inference for complex longitudinal data: the continuous case. Annals of Statistics 29: 1785-1811.

Granger CWJ. 1969. Investigating causal relations by econometric models and crossspectral methods. Econometrica 37: 424-438.

Granger CWJ. 1980. Testing for causality: a personal viewpoint. Journal of Economic Dynamics and Control 2: 329-352.

Heckman JJ. 2000. Policies to foster human capital. Research in Economics 54: 3-56.

Holland PW. 1986. Statistics and causal inference. Journal of the American Statistical Association 81: 945-960.

Holtz-Eakin D, Newey W, Rosen HS. 1988. Estimating vector autoregressions with panel data. Econometrica 56: 1371-1395.

Holtz-Eakin D, Newey W, Rosen HS. 1989. The revenue-expenditure nexus: evidence from local government data. International Economic Review 30: 415-429.

Juster FT, Stafford FP. 1991. The allocation of time: empirical findings, behavioral models, and problems of measurement. Journal of Economic Literature 29: 471-522.

Keane M, Wolpin K. 1997. Career decisions of young men. Journal of Political Economy 105: $473-522$.

Lechner M. 2004. Sequential matching estimation of dynamic causal models. University of St. Gallen, Discussion paper. 
Lechner M. 2006. The relation of different concepts of causality in econometrics. University of St. Gallen, Discussion paper.

Lechner M. 2008. Matching estimating of dynamic treatment models: some practical issues. In Advances in Econometrics 21, Millimet D, Smith J, Vytlacil E. (eds). JAI Press.

Lechner M, Miquel R. 2001. A potential outcome approach to dynamic programme evaluation - Part I: identification. Discussion paper 2001-07, Department of Economics, University of St. Gallen.

Lee MJ, Kobayashi S. 2001. Proportional treatment effects for count response panel data: effects of binary exercise on health care demand. Health Economics 10: 411-428.

Lee MJ. 2002. Panel data econometrics: methods-of-moments and limited dependent variables. Academic Press.

Pecora N, Murray JP, Wartella EA. 2006. Children and television: fifty years of research. Lawrence Erlbaum Associates.

Rideout V, Roberts DF, Foehr UG. 2005. Generation M: media in the lives of 8-18 year-olds. A Kiser Family Foundation Study, www.kff.org.

Robins JM. 1986. A new approach to causal inference in mortality studies with sustained exposure periods - Application to control of the healthy worker survivor effect. Mathematical Modelling 7: 1393-1512; Errata, 1987, Computers and Mathematics with Applications 14: 917-921; Addendum, 1987, Computers and Mathematics with Applications 14: 923-945; Errata to Addendum, 1987, Computers and Mathematics with Applications 18: 477.

Robins JM. 1998. Structural nested failure time models. In Survival Analysis 6, Encyclopedia of Biostatistics, Armitage P, Colton T (eds). Wiley.

Robins JM. 1999. Marginal structural models versus structural nested models as tools for causal inference. In Statistical models in epidemiology: the environment and clinical trials, Halloran ME, Berry D (eds). Springer.

Robins JM, Greenland S, Hu FC. 1999. Estimation of the causal effect of a time-varying exposure on the marginal mean of a repeated binary outcome. Journal of the American Statistical Association 94: 687-700.

Rosenbaum PR, Rubin DB. 1983. The central role of the propensity score in observational studies for causal effects. Biometrika 70: 41-55.

Van Evra JP. 2004. Television and child development. Lawrence Erlbaum Associates.

Zavodny M. 2006. Does watching television rot your mind? Estimates of the effect on 
test scores. Economics of Education Review 25: 565-573.

Zimmerman FJ, Christakis DA. 2005. Children's television viewing and cognitive outcomes: a longitudinal analysis of national data. Archives of Pediatrics and Adolescent Medicine 159: 619-625. 
Table 1: TV Watching and Math and Reading Scores: Summary Statistics

\begin{tabular}{|c|c|c|c|c|c|}
\hline & \multicolumn{2}{|c|}{ Daily TV watching hours } & \multicolumn{2}{|c|}{ PIAT scores at age $8-9$} & \multirow{2}{*}{$\begin{array}{l}\text { Group } \\
\text { Size }\end{array}$} \\
\hline & at age $8-9$ & at age $6-7$ & math & reading & \\
\hline Main Sample & $3.5(2.0)$ & $3.3(2.0)$ & $102.2(13.9)$ & $105(14.6)$ & 2180 \\
\hline \multicolumn{6}{|l|}{$\underline{\text { Race }}$} \\
\hline White & $2.9(1.7)$ & $2.9(1.8)$ & $106.3(13.0)$ & $108.0(13.8)$ & 1165 \\
\hline Non-White & $4.1(2.2)$ & $3.9(2.2)$ & $97.5(13.4)$ & $101.6(14.7)$ & 1015 \\
\hline \multicolumn{6}{|l|}{ Sex } \\
\hline$\overline{\text { Boy }}$ & $3.5(2.0)$ & $3.3(1.9)$ & $102.6(14.6)$ & $103.6(15.3)$ & 1095 \\
\hline Girl & $3.5(2.0)$ & $3.4(2.1)$ & $101.7(13.2)$ & $106.4(13.7)$ & 1085 \\
\hline \multicolumn{6}{|l|}{ Birth order } \\
\hline First-borns & $3.2(1.9)$ & $3.1(1.9)$ & $104.3(13.6)$ & $108.4(13.3)$ & 868 \\
\hline Others & $3.7(2.1)$ & $3.5(2.1)$ & 100.7 (13.9) & $102.7(15.0)$ & 1312 \\
\hline \multicolumn{6}{|c|}{ How many children books a child has at home at age 6-7 } \\
\hline$>=10$ at both & $3.3(1.9)$ & $3.2(2.0)$ & $103.8(13.2)$ & $106.7(13.7)$ & 1862 \\
\hline$<10$ at either & $4.6(2.2)$ & $4.1(2.2)$ & $92.6(13.2)$ & $94.6(15.4)$ & 313 \\
\hline \multicolumn{6}{|c|}{ Mother reads to child at age 6-7 } \\
\hline Often & $3.3(2.0)$ & $3.3(2.0)$ & $103.1(13.5)$ & $105.7(14.2)$ & 1636 \\
\hline Not often & $4.1(2.1)$ & $3.6(2.0)$ & $99.2(14.6)$ & $102.7(15.5)$ & 540 \\
\hline \multicolumn{6}{|c|}{ Whether parents discuss TV programs with a child } \\
\hline Discuss & $3.4(2.0)$ & $3.3(2.0)$ & $103.2(13.8)$ & $106.0(14.4)$ & 1801 \\
\hline Not discuss & $3.9(2.2)$ & $3.6(1.9)$ & $97.0(13.2)$ & $100.2(14.7)$ & 354 \\
\hline \multicolumn{6}{|l|}{ School type } \\
\hline Public & $3.5(2.0)$ & $3.4(2.0)$ & $102.6(14.4)$ & $104.8(14.7)$ & 885 \\
\hline private & $2.6(2.0)$ & $2.3(1.6)$ & $105.7(11.6)$ & $111.1(11.5)$ & 66 \\
\hline \multicolumn{6}{|c|}{ Mother's highest grade } \\
\hline$>=16$ & $2.7(1.8)$ & $2.7(1.8)$ & $107.0(13.6)$ & $109.4(13.4)$ & 534 \\
\hline$<16$ & $3.7(2.0)$ & $3.6(2.0)$ & $100.6(13.6)$ & $103.5(14.7)$ & 1646 \\
\hline \multicolumn{6}{|c|}{ Mother's AFQT score in 1981} \\
\hline Above mean & $2.7(1.6)$ & $2.7(1.7)$ & $107.5(12.5)$ & 109.9 (12.9) & 999 \\
\hline Below mean & $4.1(2.1)$ & $3.9(2.1)$ & $97.6(13.2)$ & $100.9(14.7)$ & 1181 \\
\hline \multicolumn{6}{|c|}{ Earlier PIAT scores } \\
\hline PIAT Math at & ge $6-7$ & & $100.8(12.1)$ & & 2180 \\
\hline PIAT Math at & ge $4-5$ & & $99.2(14.7)$ & & 1250 \\
\hline PIAT Reading & t age $6-7$ & & $103.3(11.7)$ & & 2180 \\
\hline PIAT Reading & t age $4-5$ & & $106.5(14.8)$ & & 1175 \\
\hline
\end{tabular}


Table 2: TV Watching on Math and Reading: Granger Causality

\begin{tabular}{|c|c|c|c|c|c|c|}
\hline & \multicolumn{3}{|c|}{ PIAT Math at age 8-9 } & \multicolumn{3}{|c|}{ PIAT Reading at age 8-9 } \\
\hline & OLS & OLS(S) & $\mathrm{OLS}(\mathrm{SH})$ & OLS & OLS(S) & $\mathrm{OLS}(\mathrm{SH})$ \\
\hline Daily TV hours at age 8-9 & $\begin{array}{c}-1.05 \\
(.77)\end{array}$ & $\begin{array}{c}-2.15 \\
(1.74)\end{array}$ & $\begin{array}{c}-2.68 \\
(2.52)\end{array}$ & $\begin{array}{c}-.06 \\
(.61)\end{array}$ & $\begin{array}{c}2.21 \\
(1.83)\end{array}$ & $\begin{array}{c}2.49 \\
(2.60)\end{array}$ \\
\hline Daily TV hours at age 8-9 squared & $\begin{array}{l}.16^{* *} \\
(.08)\end{array}$ & $\begin{array}{l}.36^{* *} \\
(.18)\end{array}$ & $\begin{array}{c}.40 \\
(.26)\end{array}$ & $\begin{array}{c}.03 \\
(.07)\end{array}$ & $\begin{array}{l}-.23 \\
(.18)\end{array}$ & $\begin{array}{l}-.25 \\
(.25)\end{array}$ \\
\hline Daily TV hours at age 6-7 & $\begin{array}{c}.89 \\
(.68)\end{array}$ & $\begin{array}{c}4.79 * * \\
(1.89)\end{array}$ & $\begin{array}{l}5.50 * * \\
(2.31)\end{array}$ & $\begin{array}{c}.58 \\
(.60)\end{array}$ & $\begin{array}{c}1.96 \\
(1.79)\end{array}$ & $\begin{array}{l}2.54 \\
(2.0)\end{array}$ \\
\hline Daily TV hours at age 6-7 squared & $\begin{array}{l}-.11 \\
(.08)\end{array}$ & $\begin{array}{c}-.56 * * * \\
(.21)\end{array}$ & $\begin{array}{c}-.66^{* *} \\
(.26)\end{array}$ & $\begin{array}{l}-.07 \\
(.07)\end{array}$ & $\begin{array}{l}-.37 * \\
(.21)\end{array}$ & $\begin{array}{c}-.57 * * \\
(.23)\end{array}$ \\
\hline PIAT score at Age 6-7 & $\begin{array}{c}.59 * * * \\
(.04)\end{array}$ & $\begin{array}{c}.58^{* * *} \\
(.12)\end{array}$ & $\begin{array}{c}.65 * * * \\
(.13)\end{array}$ & $\begin{array}{c}.78^{* * * *} \\
(.03)\end{array}$ & $\begin{array}{c}.83 * * * \\
(.09)\end{array}$ & $\begin{array}{c}.88 * * * \\
(.12)\end{array}$ \\
\hline PIAT score at Age 4-5 & $\begin{array}{c}.10^{* * *} \\
(.03)\end{array}$ & $\begin{array}{l}.13 \\
(.09)\end{array}$ & $\begin{array}{c}.12 \\
(.11)\end{array}$ & $\begin{array}{c}.09 * * * \\
(.03)\end{array}$ & $\begin{array}{c}.06 \\
(.08)\end{array}$ & $\begin{array}{c}.09 \\
(.09)\end{array}$ \\
\hline Joint Significance of TV at 6-9 & $.07^{*}$ & $.03 * *$ & $.04 * *$ & .60 & .12 & $.009 * * *$ \\
\hline Joint Significance of TV at 8-9 & $.02 * *$ & $.02 * *$ & .15 & .50 & .46 & 61 \\
\hline Joint Significance of TV at 6-7 & .38 & $.03 * *$ & $.048 * *$ & .60 & $.04^{* *}$ & $.001^{* * *}$ \\
\hline Sample Size & 871 & 178 & 155 & 835 & 175 & 152 \\
\hline R-squared & .49 & .71 & .72 & .64 & .75 & .79 \\
\hline
\end{tabular}

Mean Difference in PIAT Scores (Bootstrapped std. dev. in parentheses)

\begin{tabular}{lcccccc}
\hline \multirow{3}{*}{ Daily TV hours at age 6-9 } & \multicolumn{3}{c}{ PIAT Math at age 8-9 } & \multicolumn{3}{c}{ PIAT Reading at age 8-9 } \\
\cline { 2 - 7 } & OLS & OLS(S) & OLS(SH) & OLS & OLS(S) & OLS(SH) \\
\hline 1 hour versus 0 hour & -.12 & 2.43 & 2.56 & .49 & 3.57 & 4.20 \\
& $(.72)$ & $(2.68)$ & $(5.82)$ & $(.61)$ & $(2.44)$ & $(4.23)$ \\
& -.13 & 4.46 & 4.62 & .90 & 5.94 & 6.77 \\
hours versus 0 hour & $(1.27)$ & $(4.73)$ & $(9.95)$ & $(1.07)$ & $(4.30)$ & $(7.34)$ \\
& -.04 & 6.08 & 6.17 & 1.25 & 7.11 & 7.69 \\
hours versus 0 hour & $(1.66)$ & $(6.21)$ & $(12.5)$ & $(1.39)$ & $(5.59)$ & $(9.41)$ \\
& .15 & 7.28 & 7.21 & 1.52 & 7.07 & 6.97 \\
& $(1.9)$ & $(7.16)$ & $(13.5)$ & $(1.59)$ & $(6.38)$ & $(10.57)$ \\
& .45 & 8.08 & 7.73 & 1.72 & 5.83 & 4.61 \\
5 hours versus 0 hour & $(2.0)$ & $(7.68)$ & $(13.5)$ & $(1.67)$ & $(6.77)$ & $(11.06)$ \\
& .85 & 8.47 & 7.75 & 1.86 & 3.38 & .60 \\
6 hours versus 0 hour & $(2.0)$ & $(7.96)$ & $(13.1)$ & $(1.67)$ & $(6.95)$ & $(11.35)$ \\
& .28 & 2.82 & 2.58 & .62 & 1.13 & .20 \\
4 hours versus 2 hours & $(.67)$ & $(2.65)$ & $(4.37)$ & $(.56)$ & $(2.32)$ & $(3.78)$ \\
6 hours versus 2 hours & .98 & 4.01 & 3.13 & .95 & -2.56 & -6.16 \\
& $(1.0)$ & $(4.53)$ & $(8.73)$ & $(.88)$ & $(4.04)$ & $(7.26)$ \\
\hline
\end{tabular}

Notes: $* \mathrm{p}<.1 ; * * \mathrm{p}<.05 ; * * * \mathrm{p}<.01$. Standard deviations are in the parentheses. The sample is composed of kids watching ten hours or less TV per day at ages 6-9. The controlled inputs include a child's race, sex, birth order, home inputs at ages 6-7 and 8-9, and family backgrounds (mother's AFQT score, her age at child birth, whether the child was breastfed, her marriage status, highest grade, and family income). OLS(S) -- School inputs at ages 6-7 and 8-9 as listed in the appendix are included. OLS(SH) -- Home inputs at age 4-5 are included as well as the above school inputs. 
Table 3: TV Watching on Math and Reading: Fixed Effect Model

\begin{tabular}{|c|c|c|c|c|c|c|}
\hline & \multicolumn{3}{|c|}{ PIAT Math } & \multicolumn{3}{|c|}{ PIAT Reading } \\
\hline & \multirow{2}{*}{$\begin{array}{c}\begin{array}{c}\text { At age } \\
\mathbf{8 - 9}\end{array} \\
\text { FE (IV) }\end{array}$} & \multicolumn{2}{|c|}{$\begin{array}{c}\text { Difference } b / w \text { ages } \\
8-9 \text { and } 6-7\end{array}$} & \multirow{2}{*}{$\begin{array}{c}\text { At age } \\
\mathbf{8 - 9} \\
\text { FE (IV) }\end{array}$} & \multicolumn{2}{|c|}{$\begin{array}{c}\text { Difference } b / w \text { ages } \\
8-9 \text { and 6-7 }\end{array}$} \\
\hline & & $\mathrm{DF}$ & $\mathrm{DF}(\mathrm{S})$ & & DF & $\mathrm{DF}(\mathrm{S})$ \\
\hline $\begin{array}{l}\text { Difference in daily TV hours } \\
\text { b/w ages 8-9 and 6-7 }\end{array}$ & & $\begin{array}{l}-.18 \\
(.50)\end{array}$ & $\begin{array}{l}-1.41 \\
(1.26)\end{array}$ & & $\begin{array}{l}.084 \\
(.39)\end{array}$ & $\begin{array}{l}1.38 \\
(.90)\end{array}$ \\
\hline $\begin{array}{l}\text { Difference in squared daily TV } \\
\text { hours b/w ages 8-9 and 6-7 }\end{array}$ & & $\begin{array}{l}.02 \\
(.05)\end{array}$ & $\begin{array}{l}.14 \\
(.13)\end{array}$ & & $\begin{array}{l}-.015 \\
(.04)\end{array}$ & $\begin{array}{l}-.17^{*} \\
(.09)\end{array}$ \\
\hline Daily TV hours at age 8-9 & $\begin{array}{l}-7.90 \\
(11.3)\end{array}$ & & & $\begin{array}{l}-1.89 \\
(8.28)\end{array}$ & & \\
\hline $\begin{array}{l}\text { Daily TV hours at age 8-9 } \\
\text { squared }\end{array}$ & $\begin{array}{c}.61 \\
(1.68)\end{array}$ & & & $\begin{array}{c}.14 \\
(1.15)\end{array}$ & & \\
\hline Daily TV hours at age 6-7 & $\begin{array}{c}5.76 \\
(5.41)\end{array}$ & & & $\begin{array}{c}.92 \\
(3.68)\end{array}$ & & \\
\hline $\begin{array}{l}\text { Daily TV hours at age 6-7 } \\
\text { squared }\end{array}$ & $\begin{array}{l}-.55 \\
(.46)\end{array}$ & & & $\begin{array}{l}-.08 \\
(.34)\end{array}$ & & \\
\hline PIAT score at age 6-7 & $\begin{array}{l}.62 * * * \\
(.12)\end{array}$ & & & $\begin{array}{c}.72 * * * \\
(.10)\end{array}$ & & \\
\hline Sample Size & 1050 & 1555 & 299 & 1043 & 1539 & 299 \\
\hline R-squared & -- & .04 & .22 & -- & .06 & .27 \\
\hline
\end{tabular}

Mean Difference in PIAT Scores (Bootstrapped std. dev. in parentheses)

\begin{tabular}{lcccccc}
\hline \multirow{2}{*}{ Daily TV hours at age 6-9 } & \multicolumn{3}{c}{ PIAT Math at age 8-9 } & \multicolumn{3}{c}{ PIAT Reading at age 8-9 } \\
\cline { 2 - 7 } & FE (IV) & DF & DF(S) & FE (IV) & DF & DF(S) \\
\hline 1 hour versus 0 hour & -2.08 & -.16 & -1.27 & -.91 & .07 & 1.21 \\
& $(13.4)$ & $(.47)$ & $(1.22)$ & $(24.1)$ & $. .36)$ & $(.98)$ \\
2 hours versus 0 hour & -4.03 & -.28 & -2.26 & -1.70 & .11 & 2.10 \\
& $(22.8)$ & $(.84)$ & $(2.19)$ & $(43.2)$ & $.64)$ & $(1.77)$ \\
3 hours versus 0 hour & -5.86 & -.35 & -2.96 & -2.37 & .12 & 2.65 \\
& $(28.1)$ & $(1.11)$ & $(2.90)$ & $(57.3)$ & $(.85)$ & $(2.37)$ \\
4 hours versus 0 hour & -7.57 & -.38 & -3.38 & -2.91 & .10 & 2.88 \\
& $(29.7)$ & $(1.29)$ & $(3.36)$ & $(66.8)$ & $(1.0)$ & $(2.80)$ \\
5 hours versus 0 hour & -9.15 & -.37 & -3.51 & -3.33 & .05 & 2.77 \\
& $(28.1)$ & $(1.39)$ & $(3.61)$ & $(71.8)$ & $(1.08)$ & $(3.07)$ \\
6 hours versus 0 hour & -10.6 & -.31 & -3.37 & -3.63 & -.02 & 2.34 \\
& $(25.2)$ & $(1.41)$ & $(3.68)$ & $(72.8)$ & $(1.12)$ & $(3.22)$ \\
4 hours versus 2 hours & -3.53 & -.10 & -1.12 & -1.21 & -.13 & .24 \\
& $(8.41)$ & $(.47)$ & $(1.31)$ & $(24.3)$ & $(.57)$ & $(1.65)$ \\
6 hours versus 2 hours & -6.57 & -.03 & -1.11 & -1.93 & -.01 & .78 \\
& $(16.8)$ & $(.65)$ & $(1.92)$ & $(33.5)$ & $(.36)$ & $(1.04)$ \\
\hline
\end{tabular}

Notes: ${ }^{*} \mathrm{p}<.1 ;{ }^{* *} \mathrm{p}<.05 ; * * * \mathrm{p}<.01$. Standard deviations are in the parentheses. The sample is composed of kids watching ten hours or less TV per day between ages 6-9. The controlled inputs include a child's race, sex, birth order, home inputs at ages 6-9, and family backgrounds. FE (IV) - Current home inputs at ages 89 are instrumented by earlier home inputs at ages 4-5. DF(S) - School inputs at ages 6-9 are included. 
Table 4: TV Watching on Math and Reading: Two-Stage with Linear Model

\begin{tabular}{|c|c|c|c|c|c|c|c|c|}
\hline & \multicolumn{4}{|c|}{ PIAT Math } & \multicolumn{4}{|c|}{ PIAT Reading } \\
\hline & \multicolumn{2}{|c|}{ OLS } & \multicolumn{2}{|c|}{ OLS (S) } & \multicolumn{2}{|c|}{ OLS } & \multicolumn{2}{|c|}{ OLS (S) } \\
\hline & at $8-9$ & at $6-7$ & at $8-9$ & at 6-7 & at 8-9 & at 6-7 & at $8-9$ & at $6-7$ \\
\hline \multirow{2}{*}{$\begin{array}{l}\text { Daily TV hours at age } \\
8-9\end{array}$} & -.42 & & .20 & & .37 & & $1.27 *$ & \\
\hline & (.54) & & (.77) & & $(.48)$ & & $(.68)$ & \\
\hline \multirow{2}{*}{$\begin{array}{l}\text { Daily TV hours at age } \\
8-9 \text { squared }\end{array}$} & .06 & & .002 & & -.04 & & $-.12 *$ & \\
\hline & $(.06)$ & & $(.08)$ & & $(.05)$ & & $(.07)$ & \\
\hline \multirow{2}{*}{$\begin{array}{l}\text { Daily TV hours at age } \\
6-7\end{array}$} & .13 & -.27 & -.06 & -.74 & .18 & -.11 & -.47 & -.49 \\
\hline & $(.50)$ & (.44) & $(.76)$ & (1.04) & (.44) & (.43) & $(.67)$ & $(.97)$ \\
\hline \multirow{4}{*}{$\begin{array}{l}\text { Daily TV hours at age } \\
6-7 \text { squared } \\
\text { PIAT score at age } 6-7\end{array}$} & -.01 & .02 & .02 & .01 & -.01 & -.01 & .02 & -.01 \\
\hline & $(.05)$ & $(.05)$ & $(.08)$ & $(.12)$ & $(.05)$ & $(.05)$ & $(.08)$ & $(.10)$ \\
\hline & $.60 * * *$ & & $.64 * * *$ & & $.75^{* * *}$ & & $.78 * * *$ & \\
\hline & $(.03)$ & & $(.04)$ & & $(.03)$ & & $(.04)$ & \\
\hline Sample Size & 1594 & 1555 & 663 & 299 & 1578 & 1539 & 661 & 299 \\
\hline R-squared & .46 & .25 & .50 & .42 & .54 & .22 & .57 & .35 \\
\hline
\end{tabular}

Mean Difference in PIAT Scores

(Bootstrapped std. dev. in parentheses)

\begin{tabular}{lcccc}
\hline \multirow{2}{*}{ Daily TV hours at age 6-9 } & \multicolumn{2}{c}{ PIAT Math } & \multicolumn{2}{c}{ PIAT Reading } \\
\cline { 2 - 5 } & TSE & TSE (S) & TSE & TSE (S) \\
\hline 1 hour versus 0 hour & $-.38(.57)$ & $-.30(1.25)$ & $.42(.54)$ & $.31(1.23)$ \\
2 hours versus 0 hour & $-.64(1.0)$ & $-.54(2.20)$ & $.76(.96)$ & $.40(2.18)$ \\
3 hours versus 0 hour & $-.76(1.31)$ & $-.73(2.84)$ & $1.02(1.25)$ & $.28(2.85)$ \\
4 hours versus 0 hour & $-.75(1.50)$ & $-.86(3.23)$ & $1.19(1.42)$ & $-.06(3.29)$ \\
5 hours versus 0 hour & $-.62(1.58)$ & $-.94(3.41)$ & $1.27(1.50)$ & $-.62(3.54)$ \\
6 hours versus 0 hour & $-.35(1.61)$ & $-.96(3.51)$ & $1.28(1.53)$ & $-1.39(3.68)$ \\
4 hours versus 2 hours & $-.12(.54)$ & $-.32(1.17)$ & $.43(.51)$ & $-.46(1.23)$ \\
6 hours versus 2 hours & $-.37(.95)$ & $-.56(2.05)$ & $.52(.85)$ & $-1.78(2.15)$ \\
\hline \hline
\end{tabular}

Notes: $* \mathrm{p}<.1 ; * * \mathrm{p}<.05 ; * * * \mathrm{p}<.01$. Standard deviations are in the parentheses. The sample is composed of kids watching ten hours or less TV per day between ages 6-9. The controlled inputs include a child's race, sex, birth order, family backgrounds, and detailed current home inputs. OLS(S) - Detailed current school inputs are included. 
Table 5: TV Watching on Math and Reading: G-Estimation with Discrete Responses

\begin{tabular}{|c|c|c|c|c|c|c|c|c|}
\hline \multicolumn{9}{|c|}{ The Marginal Effects } \\
\hline & \multicolumn{4}{|c|}{ PIAT Math (higher than mean) } & \multicolumn{4}{|c|}{ PIAT Reading (higher than mean) } \\
\hline & \multicolumn{2}{|c|}{ Probit } & \multicolumn{2}{|c|}{ Probit $(\mathrm{H})$} & \multicolumn{2}{|c|}{ Probit } & \multicolumn{2}{|c|}{ Probit $(\mathrm{H})$} \\
\hline & at 8-9 & at 6-7 & at 8-9 & at $6-7$ & at 8-9 & at 6-7 & at 8-9 & at 6-7 \\
\hline High TV at age 8-9 & $\begin{array}{l}.05 \\
(.06)\end{array}$ & & $\begin{array}{l}-. .006 \\
(.07)\end{array}$ & & $\begin{array}{l}.06 \\
(.05)\end{array}$ & & $\begin{array}{l}.10^{*} \\
(.05)\end{array}$ & \\
\hline Middle TV at age 8-9 & $\begin{array}{l}-.007 \\
(.06)\end{array}$ & & $\begin{array}{l}-.07 \\
(.06)\end{array}$ & & $\begin{array}{l}-.02 \\
(.05)\end{array}$ & & $\begin{array}{l}.01 \\
(.05)\end{array}$ & \\
\hline High TV at age 6-7 & $\begin{array}{l}.05 \\
(.06)\end{array}$ & $\begin{array}{l}-.05 \\
(.06)\end{array}$ & $\begin{array}{l}.06 \\
(.06)\end{array}$ & $\begin{array}{l}-04 \\
(.06)\end{array}$ & $\begin{array}{l}-.07 * \\
(.06)\end{array}$ & $\begin{array}{l}.01 \\
(.06)\end{array}$ & $\begin{array}{l}-.07 \\
(.06)\end{array}$ & $\begin{array}{l}.01 \\
(.06)\end{array}$ \\
\hline Middle TV at age 6-7 & $\begin{array}{l}-.03 \\
(.05)\end{array}$ & $\begin{array}{l}-.04 \\
(.05)\end{array}$ & $\begin{array}{l}-.002 \\
(.06)\end{array}$ & $\begin{array}{l}-.05 \\
(.05)\end{array}$ & $\begin{array}{l}-.004 \\
(.05)\end{array}$ & $\begin{array}{l}-.001 \\
(.05)\end{array}$ & $\begin{array}{l}-.01 \\
(.05)\end{array}$ & $\begin{array}{l}.001 \\
(.05)\end{array}$ \\
\hline $\begin{array}{l}\text { PIAT score higher } \\
\text { than mean at age } 6-7\end{array}$ & $\begin{array}{l}.37 * * * \\
(.04)\end{array}$ & & $\begin{array}{l}.40 * * * \\
(.04)\end{array}$ & & $\begin{array}{l}.51 * * * \\
(.04)\end{array}$ & & $\begin{array}{l}.51^{* * *} \\
(.05)\end{array}$ & \\
\hline $\begin{array}{l}\text { PIAT score higher } \\
\text { than mean at age } 4-5\end{array}$ & $\begin{array}{l}.03 \\
(.04)\end{array}$ & $\begin{array}{l}.31^{* * *} \\
(.04)\end{array}$ & $\begin{array}{c}.04 \\
(.04)\end{array}$ & $\begin{array}{l}.26 * * * \\
(.04)\end{array}$ & $\begin{array}{l}.14 * * * \\
(.05)\end{array}$ & $\begin{array}{l}.32 * * * \\
(.05)\end{array}$ & $\begin{array}{l}.13^{* *} \\
(.05)\end{array}$ & $\begin{array}{l}.29 * * * \\
(.05)\end{array}$ \\
\hline Sample Size & 720 & 720 & 651 & 651 & 687 & 687 & 622 & 622 \\
\hline Pseudo R-squared & .29 & .23 & .31 & .22 & .40 & .26 & .41 & .23 \\
\hline
\end{tabular}

Mean difference in probability of PIAT score higher than mean at age 8-9 (Bootstrapped std. dev. in parentheses)

\begin{tabular}{lcccc}
\hline \multirow{2}{*}{ Daily TV hours at ages 6-9 } & \multicolumn{2}{c}{ PIAT Math } & \multicolumn{2}{c}{ PIAT Reading } \\
\cline { 2 - 5 } High versus Low TV at ages 6-9 & G-est. & G-est. (H) & G-est. & G-est. (H) \\
Middle versus Low TV at ages 6-9 & $-.18^{* *}$ & $-.23^{* * *}$ & $-.21^{* * *}$ & $-23^{* * *}$ \\
& $(.08)$ & $(.08)$ & $(.08)$ & $(.09)$ \\
High versus Low TV at age 6-7 with Low at 8-9 & $-.16^{* *}$ & $-.18^{* *}$ & $-.13^{*}$ & $-.14^{*}$ \\
& $(.07)$ & $(.07)$ & $(.07)$ & $(.08)$ \\
Middle versus Low TV at age 6-7 with Low at 8-9 & $-.23^{*}$ & -.19 & $-.23^{*}$ & $-.26^{*}$ \\
& $-.13)$ & $(.13)$ & $(.12)$ & $(.14)$ \\
\hline \hline
\end{tabular}

Notes: * $\mathrm{p}<.1 ; * * \mathrm{p}<.05 ; * * * \mathrm{p}<.01$. Standard deviations are in the parentheses.

High TV: watching TV more than 4 hours per day; Middle TV: more than 2 but less than or equal to 4 hours per day; Low TV: less than or equal to 2 hours per day. The sample is composed of kids watching ten hours or less TV per day between ages 6-9. The controlled inputs include a child's race, sex, birth order, detailed home inputs at ages 6-9, home environment indicators at ages 2-3 and 4-5, and family backgrounds. Probit (H) -- Detailed home inputs at age 4-5 are included. 


\section{Appendix: List of Variables and Summary Statistics}

\begin{tabular}{lrc}
\hline Variable & Mean (SD) & Size \\
\hline \hline PIAT Math at age 8-9 & $102.2(13.9)$ & 2180 \\
PIAT Math at age 6-7 & $100.8(12.1)$ & 2180 \\
PIAT Math at age 4-5 & $99.2(14.7)$ & 1250 \\
PIAT Reading at age 8-9 & $105.0(14.6)$ & 2180 \\
PIAT Reading at age 6-7 & $103.3(11.7)$ & 2180
\end{tabular}

PIAT Reading at age 4-5

$106.5(14.8) \quad 1175$

\section{(G1) Child Demographic Information}

race of child: Black or Hispanic

$\begin{array}{rr}.47(.5) & 2180 \\ .50(.5) & 2180 \\ 2.0(1.0) & 2180\end{array}$

sex of child: boy

birth order of child

$2.0(1.0)$

2180

\section{(G2) Home inputs for 8-9 years olds}

\# of hours/day child sees TV

child has 10 or more children books at home

$3.49(2.03) \quad 2180$

how often mom reads to child: at least 3 times a week

$.88(.32)$

2173

how often child reads for enjoyment: everyday

$.59(.49)$

family encourages hobbies

$.35(.48) \quad 2174$

$.93(.25) \quad 2169$

how often child taken to museum: at least several times a year

$.43(.50)$

2173

$.35(.48) \quad 2172$

how often child taken to performance: at least several times a year

$.59(.49)$

2177

how often child with dad outdoors: at least once a week

how often child eats with mom \& dad: at least once a day

$.49(.50)$

2083

parents discuss TV programs with child

$.57(.50)$

2081

$.84(.37)$

2155

\section{(G3) Home inputs for 6-7 years olds}

\# of hours/day child sees TV

child has 10 or more children books at home

how often mom reads to child: at least 3 times a week

how often child reads for enjoyment: everyday

family encourages hobbies

how often child taken to museum: at least several times a year

how often child taken to performance: at least several times a year

how often family get with relatives/friends: at least 2-3 times/month

how often child with dad outdoors: at least once a week

how often child eats with mom \& dad: at least once a day

parents discuss TV programs with child

$\begin{array}{cc}3.35(2.02) & 2180 \\ .86(.35) & 2175 \\ .75(.43) & 2176 \\ .67(.47) & 2170 \\ .91(.29) & 2173 \\ .78(.41) & 2177 \\ .61(.49) & 2178 \\ .61(.49) & 2180 \\ .50(.50) & 2134 \\ .78(.41) & 2173 \\ .83(.37) & 2168\end{array}$

\section{(G4) Home inputs for 4-5 years olds}

\# of hours/weekday child sees TV

$3.31(3.22) \quad 1505$

\# of hours/weekend day child sees TV

$3.66(3.19) \quad 1511$

\# of hours TV is on per day

how many books does child have: 10 or more books

$5.44(5.64)$

how often mother read to child: at least 3 times a week

$.82(.39) \quad 2029$

$.58(.49) \quad 2029$

how often child taken to museum: at least several times a year

$.72(.45)$

how many magazines does family get: 3 or more

$.61(.49) \quad 2024$

how often child taken on outing: at least several times a week

$.56(.50) \quad 2016$

how often child eats with mom \& dad: at least once a day

$.76(.43)$

2011

home observation measurement of the environment variable (HOME)

$206.1(34.3)$ 


\begin{tabular}{lrr}
\hline Variable & Mean (SD) & Size \\
\hline \hline \multicolumn{2}{l}{ (G5) Family Background } & \\
mother's AFQT score taken in 1981 & $41.3(28.2)$ & 2117 \\
mother's highest grade at 1988 & $12.6(2.2)$ & 2133 \\
Family salary income in 1988 & $6895.8(8414.8)$ & 2112 \\
mother was married in 1988 & $.81(.39)$ & 1819 \\
mother's age at child birth & $25.0(3.0)$ & 2179 \\
child is breastfed & $.52(.50)$ & 2085
\end{tabular}

\section{(G6) School Inputs for 8-9 years old}

hours/week a child spends on math homework hours/week a child spends on writing homework the school is public mother's rating of teacher caring - high mother's rating of principal as leader - high mother's rating of teacher skill - high mother's rating of safety of school - high mother's rating of school communicating with parents - high mother's rating of parents participating with school - high mother's rating of school teaching right and wrong - high mother's rating of school maintaining order - high mother's rating of teacher caring - middle mother's rating of principal as leader - middle mother's rating of teacher skill - middle mother's rating of safety of school - middle mother's rating of school communicating with parents - middle mother's rating of parents participating with school - middle mother's rating of school teaching right and wrong - middle mother's rating of school maintaining order - middle

$\begin{array}{ll}2.24(3.39) & 970 \\ 1.75(3.06) & 899 \\ .93(.25) & 951 \\ .60(.49) & 994 \\ .51(.50) & 991 \\ .52(.50) & 990 \\ .64(.48) & 993 \\ .57(.49) & 994 \\ .32(.47) & 991 \\ .54(.50) & 994 \\ .56(.50) & 994 \\ .31(.46) & 994 \\ .33(.47) & 991 \\ .38(.49) & 990 \\ .28(.45) & 993 \\ .31(.46) & 994 \\ .37(.48) & 991 \\ .34(.47) & 994 \\ .32(.47) & 994\end{array}$

\section{(G7) School Inputs for 6-7 years old}

hours/week a child spends on math homework hours/week a child spends on writing homework the school is public mother's rating of teacher caring - high mother's rating of principal as leader - high mother's rating of teacher skill - high mother's rating of safety of school - high mother's rating of school communicating with parents - high mother's rating of parents participating with school - high mother's rating of school teaching right and wrong - high mother's rating of school maintaining order - high mother's rating of teacher caring - middle mother's rating of principal as leader - middle mother's rating of teacher skill - middle mother's rating of safety of school - middle mother's rating of school communicating with parents - middle mother's rating of parents participating with school - middle mother's rating of school teaching right and wrong - middle mother's rating of school maintaining order - middle

$\begin{array}{ll}1.15(2.30) & 414 \\ .79(1.62) & 356 \\ .95(.22) & 450 \\ .65(.48) & 484 \\ .55(.50) & 485 \\ .55(.50) & 482 \\ .63(.48) & 486 \\ .58(.49) & 484 \\ .31(.46) & 485 \\ .58(.49) & 486 \\ .60(.49) & 484 \\ .25(.43) & 484 \\ .27(.45) & 485 \\ .34(.48) & 482 \\ .26(.44) & 486 \\ .29(.46) & 484 \\ .41(.49) & 485 \\ .30(.46) & 486 \\ .29(.45) & 484\end{array}$

